Review

\title{
Application of atomic layer deposition in fabricating high-efficiency electrocatalysts
}

\author{
Huimin Yanga, Yao Chen ${ }^{\mathrm{b}}$, Yong Qin a,* \\ a State Key Laboratory of Coal Conversion, Institute of Coal Chemistry, Chinese Academy of Sciences, Taiyuan 030001, Shanxi, China \\ b School of Life Sciences, Northwestern Polytechnical University, Xi'an 710072, Shaanxi, China
}

\section{A R T I C L E I N F}

Article history:

Received 17 May 2019

Accepted 5 July 2019

Published 5 February 2020

\section{Keywords:}

Atomic layer deposition

Electrocatalysis

$\mathrm{Pt}$

Catalyst stability

Metal-support interaction

\begin{abstract}
A B S T R A C T
Electrocatalysis is a promising approach to clean energy conversion due to its high efficiency and low environmental pollution. Noble metal materials have been studied to show high activity toward electrocatalyltic reactions, although such applications remain restricted by the high cost and poor durability of the noble metals. By precisely adjusting the catalyst composition, size, and structure, electrocatalysts with excellent performance can be obtained. Atomic layer deposition (ALD) is a technique used to produce ultrathin films and ultrafine nanoparticles at the atomic level. It possesses unique advantages for the controllable design and synthesis of electrocatalysts. Furthermore, the homogenous composition and structure of the electrocatalysts prepared by ALD favor the exploration of structure-reactivity relationships and catalytic mechanisms. In this review, the mechanism, characteristics, and advantages of ALD in fabricating nanostructures are introduced first. Subsequently, the problems associated with existing electrocatalysts and a series of recently developed ALD strategies to enhance the activity and durability of electrocatalysts are presented. For example, the deposition of ultrafine Pt nanoparticles to increase the utilization and activity of Pt, fabrication of core-shell, overcoat, nanotrap, and other novel structures to protect the noble-metal nanoparticles and enhance the catalyst stability. In addition, ALD developments in synthesizing non-noble metallic electrocatalysts are summarized and discussed. Finally, based on the current studies, an outlook for the ALD application in the design and synthesis of electrocatalysts is presented.
\end{abstract}

(C) 2020, Dalian Institute of Chemical Physics, Chinese Academy of Sciences. Published by Elsevier B.V. All rights reserved.

\section{Introduction}

With the increase in energy demands and the reduction in non-renewable fossil fuels, humanity is facing a severe energy crisis [1,2]. Developing sustainable and clean pathways to produce chemicals and fuels is vital for meeting human energy requirements and protecting the environment. Electrocatalysis is a promising method for clean energy conversion. It is able to convert molecules in the atmosphere, such as $\mathrm{H}_{2} \mathrm{O}, \mathrm{CO}_{2}$, and $\mathrm{N}_{2}$, into higher-value $\mathrm{H}_{2}$, hydrocarbons, oxygenates, and $\mathrm{NH}_{3}$ products by coupling to clean electric energy [3-7]. Additionally, it can convert the chemical energy of fuels, including $\mathrm{H}_{2}$, methanol, ethanol, and formic acid, directly into electrical energy via an efficient and clean mechanism compared to the case with other power generation methods and allows for a diverse range of applications in portable and transportation power

\footnotetext{
* Corresponding author. Tel: +86-351-4040081; E-mail: qinyong@sxicc.ac.cn

This work was supported by the National Natural Science Foundation of China $(21872160,21802094,21673269)$, the National Science Fund for Distinguished Young Scholars (21825204), the National Key R\&D Program of China (2017YFA0700101), and the Natural Science Basic Research Plan in Shaanxi Province of China (2018JQ2038).

DOI: S1872-2067(19)63440-6 | http://www.sciencedirect.com/science/journal/18722067 | Chin. J. Catal., Vol. 41, No. 2, February 2020
} 
generation [8-10].

Electrocatalysts are crucial in these energy conversion technologies for increasing the rate and selectivity of the chemical transformations involved. Pt-based catalysts have been proven to exhibit high activity in many important electrochemical reactions, such as the hydrogen evolution reaction (HER), oxygen evolution reaction (OER), oxygen reduction reaction (ORR), and electrooxidation of small-molecule alcohols and acids [5,8-11]. However, large-scale commercialization of Pt-based catalysts is restricted by the low abundance and high price of the Pt noble metal. In addition, Pt-based electrocatalysts are confronted with instability. Pt nanoparticles are usually loaded on carbon supports with a high surface area and good conductivity to provide more active sites and improve the Pt utilization. However, carbon materials are prone to be oxidized to $\mathrm{CO}_{2}$ under the severe conditions of the electrochemical environment, such as high humidity, high potentials, and high oxygen concentrations. The corrosion of carbon supports can induce the detachment and agglomeration of Pt nanoparticles and the subsequent degradation of the Pt catalytic activity. The weak interaction between Pt and carbon supports also leads to the migration and coalescence of Pt nanoparticles. Furthermore, in the electrooxidation of methanol, ethanol, formic acid, etc., the intermediate products, e.g., CO, can be strongly adsorbed on the surface of $\mathrm{Pt}$ and result in catalyst poisoning. Therefore, the development of electrocatalysts with both high activity and stability is imperative.

Intensive efforts have been devoted to enhancing the catalytic properties of Pt electrocatalysts. Reducing the size of Pt to small nanoparticles, clusters or even single atoms can expose more Pt active sites per unit mass, thus significantly increasing the catalyst activity and improving Pt utilization. Pt clusters below $0.5 \mathrm{~nm}$ loaded on graphene nanosheets exhibited an extremely higher activity toward methanol electrooxidation in comparison with that of a commercial $20 \mathrm{wt}$ \% Pt/C black catalyst [12]. Pt single atoms showed a 4-times-higher mass activity toward the HER than that of commercial Pt/C [11]. Meanwhile, manufacturing core-shell structures with Pt as the shell and a second metal as the core can also decrease the Pt usage and enhance the catalytic properties. The composition of core-shell nanoparticles and the thickness of the Pt shell significantly affect the catalyst activity. Pt-Pd core-shell nanoparticles with a shell thickness of one monolayer of Pt exhibited a 5-fold activity enhancement toward the ORR over that of monometallic Pt nanoparticles. The improved catalytic activity of this core-shell structure originated from the nanosize- and mismatch-induced surface contraction, which weakened the oxygen binding energy on the Pt surface and facilitated the ORR process [13].

To inhibit the migration and agglomeration of Pt nanoparticles and improve the stability of Pt electrocatalysts, materials more corrosion-resistant than carbon black, e.g., $\mathrm{ZrC}, \mathrm{SiC}, \mathrm{TiO}_{2}$, and $\mathrm{TiB}_{2}$, have been utilized as catalyst supports [14-17]. Increasing the interaction between Pt and the support can also help to stabilize the Pt nanoparticles. Studies have shown that doping carbon supports with heteroatoms such as sulfur, nitrogen, or phosphorus can effectively stabilize Pt nanoparticles
[18-20]. Pt catalysts incorporated with metal oxide supports exhibit enhanced electrocatalytic activity and stability due to the strong metal-support interactions [21-23]. For example, a strong metal-support interaction led to a Pt-O bond formation between Pt clusters and $\mathrm{TiO}_{2}$ and ultrahigh stability of Pt nanoparticles. The synthesized $\mathrm{Pt} / \mathrm{TiO}_{2}$ catalyst lost only $5.6 \%$ of its initial activity toward the HER, while the commercial Pt/C lost $27.9 \%$ of its initial activity after the accelerated degradation tests [15]. Encapsulation of Pt nanoparticles in a metal oxide is also an effective way to stabilize Pt catalysts, while the content and structure of the metal oxide should be carefully modulated [24].

Notwithstanding these advancements, it is still challenging to precisely control the constituent, size, and morphology of electrocatalysts to achieve the desired activity and stability using traditional methods. Atomic layer deposition (ALD) produces ultrathin films or ultrafine nanoparticles through successive and alternative surface reactions between gaseous precursors and a substrate surface [25,26]. The self-limiting nature of ALD makes it possible to deposit conformal and uniform films or nanoparticles on high-aspect-ratio structures, and the film thickness and particle size can be controlled at the atomic level [27]. ALD for electrocatalyst synthesis has been rapidly developed in the past few years. In this review, state-of-the-art developments in ALD applications toward the design and synthesis of electrocatalysts are presented. Firstly, some fundamental studies on ALD are given. Based on these studies, different strategies for improving the efficiency and stability of noble metal Pt electrocatalysts are discussed. Secondly, the synthesis of desirable noble bimetallic electrocatalysts via the ALD method, particularly bimetallic electrocatalysts with a core-shell structure is introduced. Lastly, the ALD production of non-noble metal electrocatalysts, such as transition metal oxides, nitrides, sulfides, and carbides is demonstrated.

\section{Noble monometallic Pt electrocatalysts}

\subsection{The mechanism of Pt ALD}

Understanding the ALD mechanism can help to better control the deposition and obtain materials with desirable morphologies and structures. Pt ALD represents a typical metal ALD. Here, we adopt Pt ALD as an example to briefly introduce the ALD mechanism. During the Pt ALD process, two kinds of substances participate in the reactions: Pt organometallic precursor and counter reactant. Taking the reaction of (methylcyclopentadienyl)trimethylplatinum ( $\mathrm{MeCpPtMe}_{3}$ ) and $\mathrm{O}_{2}$ as a model, the Pt ALD process contains the following steps. (i) The substrate is exposed to the $\mathrm{MeCpPtMe}_{3}$ vapor, and the $\mathrm{MeCpPtMe}_{3}$ molecules react with the oxygen functional groups on the substrate surface. The ligands of $\mathrm{MeCpPtMe}_{3}$ are partially oxidized, producing $\mathrm{H}_{2} \mathrm{O}$ and $\mathrm{CO}_{2}$ as byproducts. The reaction stops when the oxide groups on the substrate surface are depleted. (ii) The unreacted precursor molecules and byproducts are purged by an inert gas. (iii) The substrate is exposed to $\mathrm{O}_{2}$. The Pt precursor molecules chemisorbed on the substrate surface are completely oxidized, and Pt atoms are produced. 


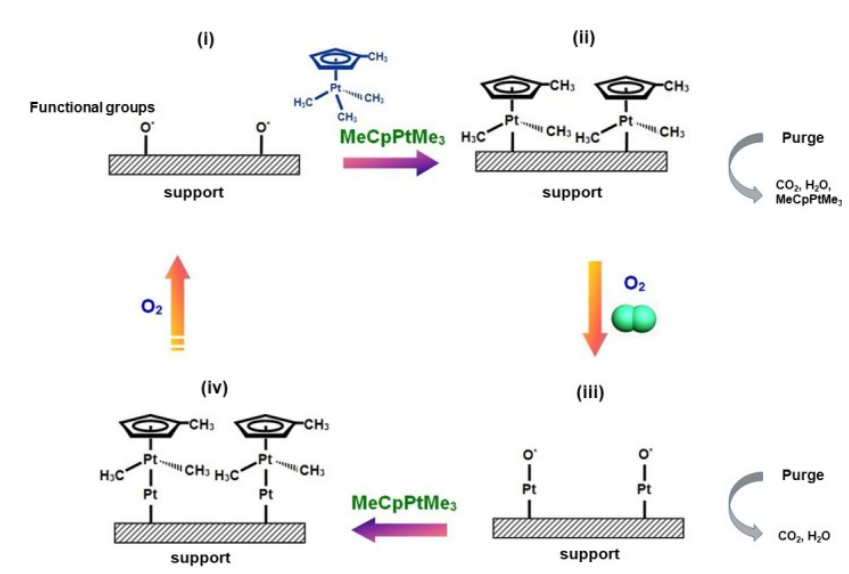

Fig. 1. Schematic of the Pt ALD mechanism [31]. (C) Springer Nature Publishing AG 2013.

Meanwhile, a new layer of oxygen functional groups is formed on the surface of Pt (Fig. 1). By alternatingly exposing the substrate to $\mathrm{MeCpPtMe}_{3}$ and $\mathrm{O}_{2}$, the two reactions proceed individually and terminate automatically once the surface reactive sites are consumed. By repeating the above steps, Pt is deposited on the surface of the substrate [28-30]. At the initial stage of ALD, the Pt nanoparticles undergo island growth owing to their weak infiltration between the Pt precursor and substrate or to the limited number of active sites on the substrate surface. When conducting further ALD cycles, the Pt nanoparticles coalesce and form a continuous Pt film. Owing to the self-limiting nature of ALD, the size of the Pt particles and the thickness of the Pt film can be controlled at the atomic level by adjusting the number of ALD cycles.

\subsection{The effect of carbon supports on the ALD process}

Carbon materials with good conductivity and high specific surface area are suitable and widely applied supports for electrocatalysts. Though Pt, Pd, and some other metal nanoparticles have been successfully deposited on carbon materials to produce high-efficiency electrocatalysts, pristine carbon supports are actually unfavorable for ALD owing to the absence of functional groups [32-34]. Here, functional groups refer to some oxygen-containing groups and ionic species on the substrate surface. They play a vital role since nucleation occurs at these active sites upon initiation of ALD. The chemically inert surfaces of pristine carbon materials lack adequate functional groups, and this will result in nucleation delay and island growth when the ALD process is initiated [35-37].

Increasing the number of functional groups on the surface of a carbon support can provide more active sites for the ALD nucleation and promote uniform deposition. A variety of methods to create functional groups on carbon supports has been reported. Hsueh et al. [37] found that an $\mathrm{HNO}_{3}$ pretreatment could implant oxygen groups including ether (C-O), carbonyl $(\mathrm{C}=0)$, and carboxyl $(\mathrm{O}-\mathrm{C}=0)$ on the surface of the carbon nanotubes (CNTs). Subsequently, dense and uniform Pt nanoparticles could be synthesized on the surface of the pretreated CNTs, while few Pt nanoparticles were formed on the surface of pristine CNTs when applying the same number of Pt ALD cycles [38]. Perng et al. [39] discovered that the number of oxygen-containing functional groups on the surface of the CNTs could be increased by prolonging the acid treatment time. The authors deposited Pt nanoparticles via the ALD method on CNTs pretreated with nitric acid for $9 \mathrm{~h}$ and incorporated the synthesized Pt/CNT catalyst into a membrane electrode assembly (MEA). The MEA, composed of an ALD-deposited anode (with a Pt loading of $0.019 \mathrm{mg} \mathrm{cm}^{-2}$ ) and cathode (with a Pt loading of $0.044 \mathrm{mg} \mathrm{cm}^{-2}$ ), exhibited a specific power density in an $\mathrm{H}_{2} / \mathrm{O}_{2}$ PEMFC that was 11-times higher than that of the MEA composed of commercial Pt/C electrodes (with a Pt loading of $0.5 \mathrm{mg} \mathrm{cm}^{-2}$ ) [39]. Hsieh et al. [40] reported that the oxygen-containing functional groups on graphene oxide (GO) not only favored the dispersion of Pt nanoparticles but also facilitated the oxidation of strongly adsorbed $\mathrm{CO}$ intermediates and the regeneration of poisoned Pt sites, thereby enhancing the activity and CO-resistance stability in the formic acid electrooxidation reaction. $\mathrm{H}_{2} \mathrm{SO}_{4}, \mathrm{HClO}_{4}$, and citric acid can also be used to create oxygen-containing groups on the surface of carbon supports $[29,41,42]$.

In addition to liquid-phase acid oxidation, gas-phase functionalization routes have been developed. Dameron et al. [43] functionalized CNT arrays using either molecular deposition to create a trimethylaluminum (TMA) monolayer, which could offer a chemical site that is more reactive with the Pt ALD precursor, or $\mathrm{O}_{2}$ plasma to increase the defect density and number of oxygen-containing functional groups on the surface of the CNTs. Both TMA and $\mathrm{O}_{2}$-plasma treatments could facilitate Pt nucleation and accelerate the ALD growth rate [43]. Qin et al. [44] used $\mathrm{O}_{3}$ as the counter reactant, instead of $\mathrm{O}_{2}$, during the Pt ALD process, producing homogenous Pt particles on the surface of the CNTs. $\mathrm{O}_{3}$ could in situ activate the CNT surface during the ALD reaction; thus, a pre-functionalization treatment could be omitted [44]. Pt ALD, with $\mathrm{O}_{3}$ as the counter reactant, exhibits a higher growth rate than that with $\mathrm{O}_{2}$ [45]. The usage of $\mathrm{O}_{3}$ can also result in a deposition temperature as low as $150{ }^{\circ} \mathrm{C}$, whereas most Pt ALD experiments are conducted at $300{ }^{\circ} \mathrm{C}$ with $\mathrm{O}_{2}$ as the counter reactant [45]. The low deposition temperature is suitable for substrates with poor thermostability.

Doping carbon materials with nitrogen benefits the dispersion of Pt nanoparticles as well [46,47]. Stambula et al. [48] synthesized $\mathrm{N}$-doped graphene by heating graphene at $900{ }^{\circ} \mathrm{C}$ in an $\mathrm{NH}_{3} / \mathrm{Ar}$ atmosphere. Diverse $\mathrm{N}$-dopant species, consisting of amino, pyridinic, and pyrrolic dopants, infiltrated the graphene lattice by forming covalent bonds, while the basic structure of graphene was preserved. The $\mathrm{N}$-dopants helped to stabilize Pt; only single atoms and clusters (but no nanoparticles) of Pt were formed on the N-doped graphene, even after 150 cycles of Pt ALD [48].

\subsection{The metal-support interactions synthesized by ALD}

A strong metal-support interaction (SMSI) plays an important role in enhancing the catalytic activity and stability by improving the charge redistribution between the metal and 


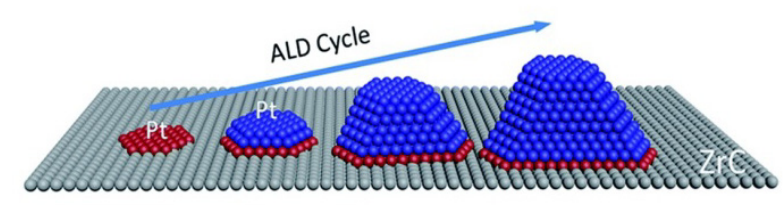

Fig. 2. Schematic of the ALD-Pt growth on a ZrC support [14]. (C) The Royal Society of Chemistry 2015.

support [49]. This action usually occurs between a metal and oxide support, and it is achieved through a high-temperature treatment in a reducing atmosphere. However, high temperatures can induce the sintering of metal nanoparticles and also induce oxide migration onto the surface of the metal particles, thereby blocking the active catalytic sites on the surface of the metal [50].

The weak interaction between Pt and carbon supports of the catalysts synthesized through conventional chemical reduction methods is one of the reasons for the aggregation of the Pt nanoparticles and the consequent degradation of the Pt catalytic activity [24,51]. When synthesizing Pt catalysts by chemical reduction methods, Pt nanoparticles are firstly formed in a solution and subsequently attached to the surface of the support mainly through physical adsorption. Whereas ALD-prepared metal catalysts are considered to possess a relatively strong interaction between the metal nanoparticles and the support. While using the ALD method, Pt precursor molecules adsorb on the surface of the support through strong chemical bonds, and the physically adsorbed precursor molecules are purged with inert gas. As the number of ALD cycles increases, $\mathrm{Pt}$ is produced layer by layer by chemical reactions between the precursor molecules and counter reactants; eventually, nanoparticles are formed on the surface of the support. This method for growing Pt NPs contributes to the strong interaction between the metal and support (Fig. 2).

Sun's group [14] compared the Pt/ZrC catalysts synthesized by a conventional chemical reduction method (denoted as CW-Pt/ZrC) with those by the ALD method. It was found that the ALD-Pt nanoparticles were hemispherically shaped on the $\mathrm{ZrC}$ surface, and the lattices of $\mathrm{Pt}(111)$ and $\mathrm{ZrC}(111)$ were well matched, while the CW-Pt nanoparticles were spherically shaped on the $\mathrm{ZrC}$ surface. In addition, XANES showed that the $\mathrm{Pt} / \mathrm{ZrC}$ catalysts prepared by the ALD method possessed a relatively high total unoccupied density of states with a Pt $5 d$ character. These results confirmed the existence of an enhanced interaction between the ALD Pt nanoparticles and $\mathrm{ZrC}$. The strong metal-support interaction adjusted the Pt electronic state, resulting in intermediate binding energy for oxygen on the Pt surface, and finally contributed to an improved ORR activity. The strong interaction between $\mathrm{Pt}$ and $\mathrm{ZrC}$ for ALD-Pt/ZrC also helped to enhance the catalyst stability, with a $17 \%$ loss of initial electrochemical surface area (ECSA) on ALD-Pt/ZrC after accelerated durability tests, whereas the ECSA decreased by $52 \%$ and $78 \%$ for $\mathrm{CW}$ - Pt/ZrC and commercial Pt/C, respectively [14]. Saha et al. [52] investigated the metal-support interaction of an ALD-synthesized $\mathrm{Pt} / \mathrm{Mo}_{2} \mathrm{C}$ catalyst by surveying the lattice spacing of the crystal particles by HRTEM. The lattice spacing was $0.26 \mathrm{~nm}$ for bare $\mathrm{Mo}_{2} \mathrm{C}$ and $0.21 \mathrm{~nm}$ for $\mathrm{Pt}(111)$. On the ALD-synthesized $\mathrm{Pt} / \mathrm{Mo}_{2} \mathrm{C}$, it was found that the $\mathrm{Pt}(111)$ fringes were expanded to $0.24 \mathrm{~nm}$ for small Pt particles. For relatively large Pt nanoparticles, the lattice spacing was approximately $0.21 \mathrm{~nm}$ in the center area, and it was expanded to $0.24 \mathrm{~nm}$ near the edge. This phenomenon of lattice expansion demonstrated the strong interaction between the ALD Pt and $\mathrm{Mo}_{2} \mathrm{C}$. The strong interaction between the metal and support in $\mathrm{ALD}$-synthesized $\mathrm{Pt} / \mathrm{Mo}_{2} \mathrm{C}$ enhanced the catalytic activity and stability. The ALD Pt/ $\mathrm{Mo}_{2} \mathrm{C}$ catalyst with a 4.4\% Pt loading exhibited a comparable HER activity to that of a commercial $20 \mathrm{wt} . \% \mathrm{Pt} / \mathrm{C}$; no decrease in current density was observed for the $\mathrm{Pt} / \mathrm{Mo}_{2} \mathrm{C}$ ALD after the 48-h durability test, while the commercial Pt/C lost $24 \%$ of its initial current density [52].

\subsection{Pt electrocatalysts designed by ALD}

\subsubsection{Fabricating highly active Pt electrocatalysts through ALD}

Improving the utilization of $\mathrm{Pt}$ is immensely required considering the low abundance and high price of Pt. Decreasing the Pt particle size can provide more active sites, thus reducing the Pt usage and catalyst cost. Pt with a diameter ranging from those of single atoms to clusters and to nanoparticles has been deposited on various supports through ALD by simply adjusting the ALD cycle number. Hsieh et al. [29] synthesized highly dispersed Pt nanoparticles with an average diameter of approximately $2.1 \mathrm{~nm}$ on a carbon powder (CP) support through ALD. The catalyst presented an ultralow Pt loading of $0.05 \mathrm{mg}$ $\mathrm{cm}^{-2}$, nearly ten times less than that of commercial Pt/C $(0.47$ $\mathrm{mg} \mathrm{cm}-2$ ), but it exhibited a higher activity toward methanol electrooxidation and a better CO tolerance. The apparent activation energies for both the dehydrogenation of methanol $\left(I_{F}\right.$, direct methanol oxidation pathway) and the oxidation of adsorbed $\mathrm{CO}$ intermediates $\left(I_{\mathrm{B}}\right.$, indirect methanol oxidation pathway) were determined to be smaller on ALD-Pt than on commercial $\mathrm{Pt} / \mathrm{C}$, indicating a lower potential barrier on the ALD Pt/CP catalyst. This was ascribed to the small Pt particle size and oxidized Pt surface that effectively accelerated the dissociative adsorption of methanol and promoted the oxidation of CO intermediates adsorbed on Pt sites [29]. A single-atom Pt/graphene catalyst fabricated by ALD exhibited a dramatically improved methanol electrooxidation activity (approximately 10 times higher than that of the state-of-the-art commercial Pt/C catalyst). X-ray absorption fine structure (XAFS) analyses ascribed this improvement to the low-coordination and partially unoccupied density of states of the $5 d$ orbital of Pt atoms [31]. Single Pt atoms supported on $\mathrm{N}$-doped graphene were also fabricated through ALD and exhibited a greatly enhanced HER activity (approximately 37 times higher) and high stability compared with those of the commercial Pt/C catalyst [18].

Three-dimensional (3D) supports possess a large specific surface area and high porosity, which can offer a highly accessible electrochemical surface and facilitate mass and electron transfers during the electrocatalytic reactions. The usage of monolithic, porous, and conductive 3D supports can also pre- 
vent the addition of polymeric binders, surfactants, and other additives, which are required when preparing a catalyst coating for the electrode with a powder catalyst and which often cause problems of dead volumes, blocking of active sites, and obstruction of mass and charge transfers. Depositing materials onto the inner surface of 3D supports with a high aspect ratio is challenging. It is difficult to create uniform particles or a continuous thin film by solution deposition techniques, and the support collapses easily once the solution is removed. Chemical vapor deposition and sputter deposition techniques have limited penetration into deep interior surfaces. ALD allows for the conformal and uniform coating of nanoparticles or thin films on complex 3D structures by employing saturated, self-limiting surface chemistry reactions. Nayak et al. [53] synthesized a Pt-based catalyst with a monolithic laser-scribed graphene scaffold (LSG) as a support through the ALD method. The SEM elemental mapping illustrated that the entire LSG was covered by uniform and conformal Pt nanoparticles. Owing to the ultrafine and homogenous Pt nanoparticles, the ALD Pt/LSG catalyst with an ultralow loading of $0.04 \mathrm{mg} \mathrm{cm}^{-2}$, nearly an order of magnitude lower than that of commercial $10 \mathrm{wt} . \% \mathrm{Pt} / \mathrm{C}(0.5$ $\mathrm{mg} \mathrm{cm}-2$ ), exhibited a very similar HER performance to that of the control [53]. Figure 3 illustrates the ultrafine and uniformly dispersed Pt particles deposited on various supports through the ALD method.

In addition to nanoparticles, various nanostructures of Pt have been successfully synthesized through ALD and applied in electrochemical reactions. Bent et al. [55] deposited a uniform Pt film on a graphite surface using active $\mathrm{O}_{3}$ as the counter reactant, whereas Pt was only deposited on the step edges of the graphite surface and formed Pt nanowires when $\mathrm{O}_{2}$ was used as the counter reactant. Cheng et al. [56] fabricated ordered hollow Pt nanotube arrays (NTAs) by ALD using ZnO nanorod arrays as a template. The Pt NTAs presented improved metha-

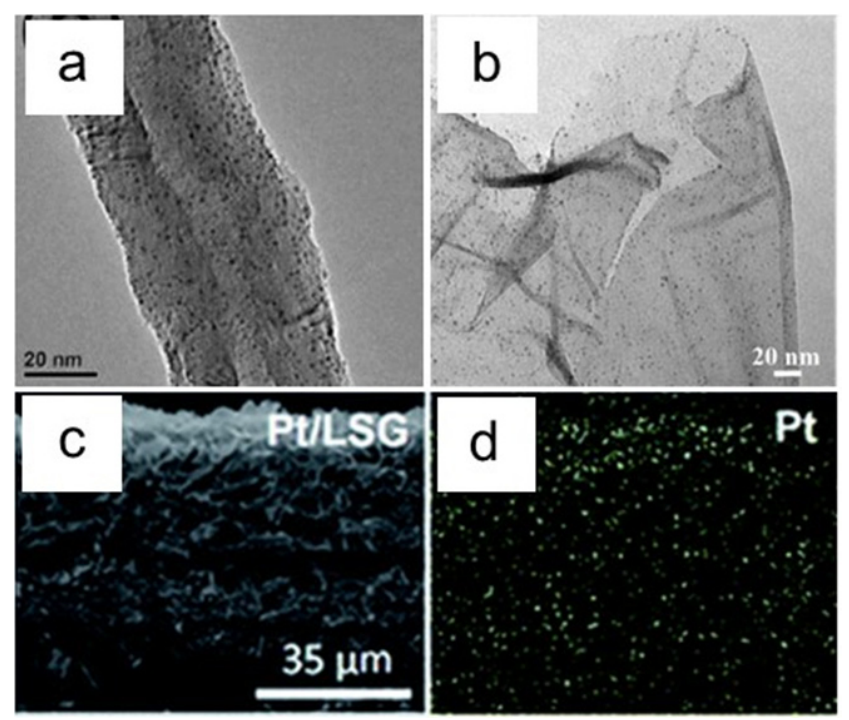

Fig. 3. (a) TEM images of ultrafine and uniform Pt nanoparticles deposited via ALD on 1D CNTs [54]. (c) The Royal Society of Chemistry 2017. (b) 2D graphene [31]. (C) Springer Nature Publishing AG 2013. (c) Cross-sectional SEM images of a 3D graphene scaffold and (d) its corresponding elemental mapping image for Pt [53]. (C) The Royal Society of Chemistry 2017. nol electrooxidation activity and CO tolerance in comparison with those of a commercial Pt/C catalyst owing to the 3D porous hollow structures and abundant Pt active sites [56]. A robust 3D porous Pt structure was created by initially depositing $\mathrm{Pt}$ on a zeolite and subsequently digesting the silica template using hydrogen fluoride. The fully connected Pt structures exhibited significant impedance improvement and remarkable HER performance in comparison with those of the reference $\mathrm{Pt}$ electrodes [57].

\subsubsection{Enhancing the stability of Pt electrocatalysts by the ALD method}

Pt nanoparticles undergo dissolution and coalescence under severe electrochemical conditions, resulting in the reduction of their active specific surface and catalytic activity. Different strategies have been developed to improve the stability of Pt electrocatalysts. Overcoating a conformal oxide or carbon film can help stabilize metal nanoparticles from migration and agglomeration. However, poor film layers cover the catalyst surface and increase the mass transfer resistance, resulting in the loss of catalytic activity. ALD has been studied as a powerful method to deposit protective overcoats since the composition and thickness of the overcoating films can be precisely controlled at the atomic level to minimize the mass transport resistance. Lu et al. [58] discovered that 1-16 cycles of $\mathrm{Al}_{2} \mathrm{O}_{3} \mathrm{ALD}$ on Pd remarkably inhibited the sintering of the metal nanoparticles without decreasing the catalyst activity toward methanol decomposition reaction. Within 16 cycles of $\mathrm{ALD}, \mathrm{Al}_{2} \mathrm{O}_{3}$ preferentially nucleated and grew at the edges and corners of $\mathrm{Pd}$, which were not active catalytic active sites for the reaction. Increasing the ALD cycles induced the gradual coverage of active catalytic $\mathrm{Pd}(111)$ sites and the degradation of the catalyst activity. Upon conducting 32 and more $\mathrm{Al}_{2} \mathrm{O}_{3} \mathrm{ALD}$ cycles, the $\mathrm{Pd}$ nanoparticles were completely encapsulated and deactivated [58].

When depositing protective overcoat films, it is crucial to create pores within the ALD overcoat to allow the reagents access the metal particles. Several methods have been proposed to generate and control the porosity within ALD films.

(i) High-temperature treatment. By removing the ALD-derived carbon residues and excluding the dehydration effect, pores can be generated within oxide films after high-temperature treatment. For example, new pores with diameters of approximately $2 \mathrm{~nm}$ were generated in an ALD $\mathrm{Al}_{2} \mathrm{O}_{3}$ overcoat after treatment at $700{ }^{\circ} \mathrm{C}$ for $2 \mathrm{~h}$ in $10 \% \mathrm{O}_{2} / \mathrm{He}$. CO DRIFTS showed that by increasing the temperature of the heat treatment from 500 to $700{ }^{\circ} \mathrm{C}$, the intensity of the CO chemisorption peaks on Pd gradually increased, indicating that a more porous structure was generated to provide access to the Pd sites for the reagent [59]. Porous carbon films can be obtained by carbonizing organic polymer films at a high temperature in an inert or $\mathrm{H}_{2}$ atmosphere. Qin et al. [47] overcoated porous $\mathrm{N}$-doped carbon films on a Pt/CNT catalyst by carbonizing ALD polyimide films at $600{ }^{\circ} \mathrm{C}$ for $2 \mathrm{~h}$ in $5 \% \mathrm{H}_{2} / \mathrm{N}_{2}$. The activity and stability of the catalyst toward methanol electrooxidation were remarkably enhanced due to the protective effect of the overcoated porous carbon films [47]. 
(ii) Organic-inorganic hybridization. Organic-inorganic hybrid films can be produced by utilizing organic counter reactants during the ALD process. After removing the organic section within the film at high temperatures, pores are in situ generated. Theoretically, a more porous structure can be obtained through this method owing to the abundant existence of organic components in the hybrid films. The pore size can be modulated by changing the molecular length of the counter reactant. Weimer et al. [36] deposited a high porous $\mathrm{Al}_{2} \mathrm{O}_{3}$ coating on $\mathrm{Pd}$ nanoparticles by oxidizing aluminum alkoxide hybrid polymer films. The hybrid films were produced through the molecular layer deposition (MLD) method using trimethylaluminum (TMA) and ethylene glycol as reactants. The Pd dispersion just decreased from $65 \%$ to $38 \%$ after applying 40 MLD cycles and subsequent calcination, demonstrating the high porosity of the $\mathrm{Al}_{2} \mathrm{O}_{3}$ overcoat.

(iii) Area-selective deposition. By area-selective atomic layer deposition, oxide overcoats can be selectively deposited on supports. Sun et al. [24] employed area selective ALD to encapsulate Pt nanoparticles in $\mathrm{ZrO}_{2}$ nanocages. First, Pt nanoparticles were deposited on N-doped CNTs. Afterward, oleylamine was used as a blocking agent to cover the Pt surface. $\mathrm{ZrO}_{2}$ was selectively deposited around the Pt nanoparticles, but not on the surface of Pt, and an open or holey zirconia nanocage was finally formed with increasing the ALD zirconia cycles. The schematic diagram for fabricating $\mathrm{Pt}$ encapsulated in $\mathrm{ZrO}_{2}$ nanocages by area-selective ALD is presented in Fig. 4. Eventually, the oleylamine group on the surface of Pt was removed by heating the catalyst at $200{ }^{\circ} \mathrm{C}$ in an oxygen atmosphere. The synthesized $\mathrm{ALD} 50 \mathrm{ZrO} 2-\mathrm{Pt} / \mathrm{NCNT} 600^{\circ} \mathrm{C}$ catalyst exhibited excellent stability toward the ORR. After accelerated durability tests, the ECSA decreased by $8 \%$ for the ALD50ZrO 2 - $\mathrm{Pt} / \mathrm{NCNT} 600^{\circ} \mathrm{C}$ catalyst, while it decreased by $74 \%$ and $82 \%$ for ALDPt/NCNT and Pt/C, respectively. This result is ascribed to the encapsulation by $\mathrm{ZrO}_{2}$ nanocages, which could inhibit Pt nanoparticles from agglomeration and migration. Furthermore, the ALD $\mathrm{ZrO}_{2}-\mathrm{Pt} / \mathrm{NCNT}$ also exhibited an improved ORR activity owing to the synergetic effects of Pt and $\mathrm{ZrO}_{2}$ [24].

The frequently used carbon supports for Pt electrocatalysts are prone to corrosion and collapse in the electrochemical environment, which aggravates the detachment and agglomeration of Pt nanoparticles. The integration of carbon materials with metal oxides, which have an intrinsically high electrochemical stability, can restrain the corrosion of the carbon support. Additionally, the strong interaction between metal oxides and Pt may also promote the catalytic activity and stability of Pt nanoparticles. Nevertheless, metal oxides usually have low electrical conductivity, which is detrimental to electrochemical reactions. Therefore, precise control of the loading and positioning of metal oxides is crucial for optimizing the properties of carbon-metal oxide composites. Marichy et al. [60] selectively deposited $\mathrm{SnO}_{2}$ on the carbon fiber (CF) support of a Pt/CF catalyst to enhance the catalyst stability (Fig. 5a). Since the deposited $\mathrm{SnO}_{2}$ was ultra-thin (approximately 1 $\mathrm{nm}$ ), the conductivity of Pt/CF was not affected. No loss of activity toward the ORR was noted after depositing $\mathrm{SnO}_{2}$, owing to the unchanged Pt exposed surface and CF conductivity. The $\mathrm{SnO}_{2}$ deposition on the CF surface greatly enhanced the stability of the Pt nanoparticles. The amount of Pt nanoparticles remaining on the surface of the CFs was substantially higher on $\mathrm{SnO}_{2}$-Pt/CFs than on Pt/CFs after the stability test (Fig. $5 \mathrm{~b}$ and
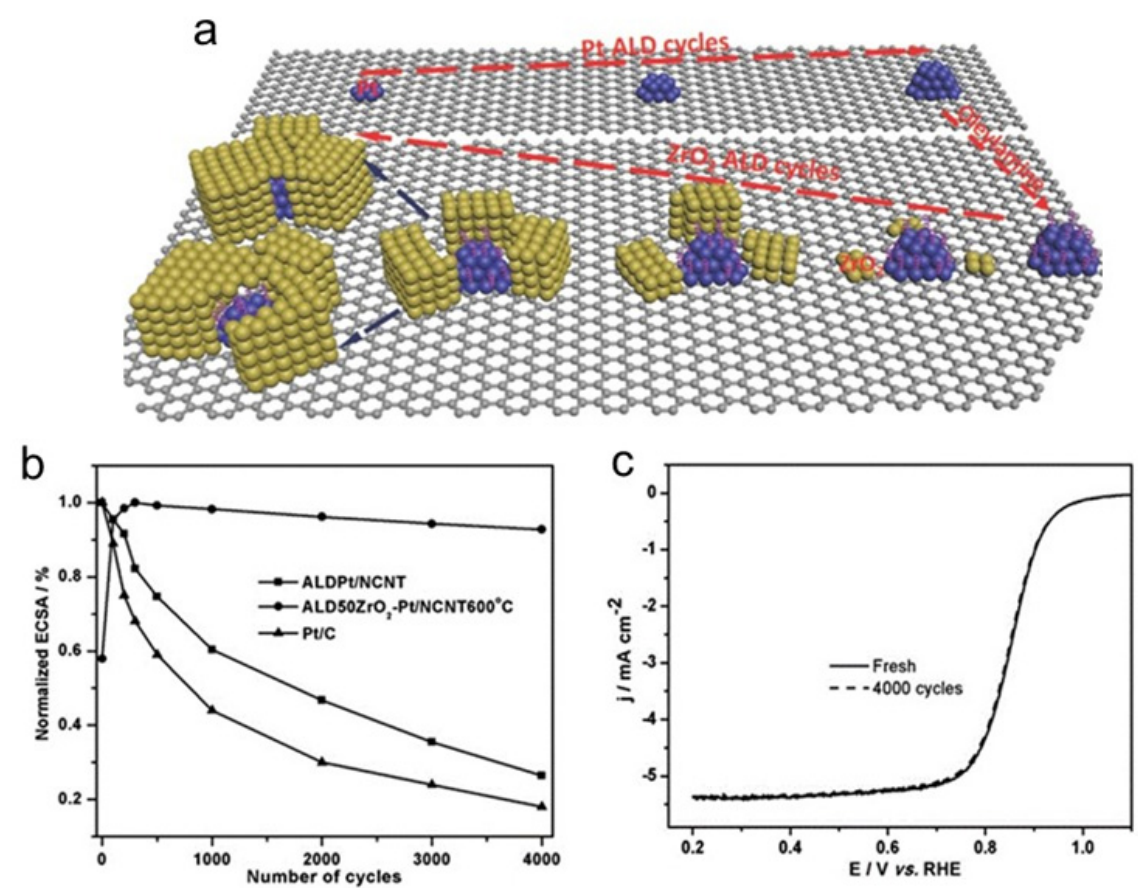

Fig. 4. (a) Schematic diagram for the fabrication of the Pt nanoparticles encapsulated in $\mathrm{ZrO}_{2}$ nanocages by area-selective ALD. (b) Loss of the electrochemical surface areas of the ALD Pt/NCNT, ALD50ZrO 2 -Pt/NCNT600 ${ }^{\circ} \mathrm{C}$, and E-TEK Pt/C catalysts. (c) $\mathrm{ORR}$ curves of ALD50ZrO ${ }_{2}-\mathrm{Pt} / \mathrm{NCNT} 60{ }^{\circ} \mathrm{C}$ obtained during the durability test [24]. (C) Wiley-VCH 2014. 

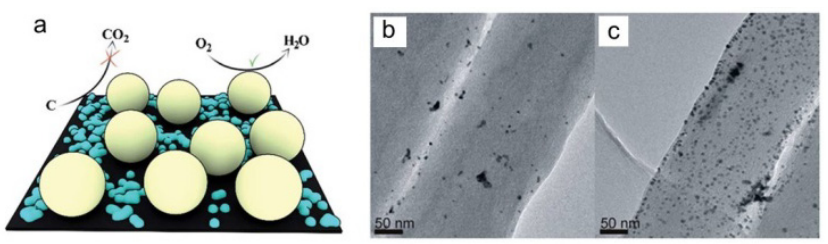

Fig. 5. (a) Schematic diagram of $\mathrm{SnO}_{2}$ selectively deposited on the support of a Pt/CF catalyst, impeding the carbon support from being oxidized to $\mathrm{CO}_{2}$ during the ORR. (b) TEM images of Pt/CF and $\mathrm{SnO}_{2}-\mathrm{Pt} / \mathrm{CF}$ after the stability test [60]. (C) The Royal Society of Chemistry 2016.

5c). In addition, the size of the Pt nanoparticles increased from $2 \mathrm{~nm}$ to $7 \mathrm{~nm}$ and $4.9 \mathrm{~nm}$ for Pt/CFs and $\mathrm{SnO}_{2}$-Pt/CFs, respectively. These results indicated that the agglomeration and detachment of Pt nanoparticles were significantly suppressed by the strong interaction between $\mathrm{Pt}$ and $\mathrm{SnO}_{2}$ [60].

The stability of Pt electrocatalysts can also be improved by selecting highly corrosion-resistant support materials. Sun et al. [14] synthesized a robust ORR catalyst by depositing Pt nanoparticles on a $\mathrm{ZrC}$ support with good conductivity and electrochemical corrosion resistance. The prepared ALD-Pt/ZrC exhibited excellent catalytic activity and stability compared with those of commercial $\mathrm{Pt} / \mathrm{C}$ and $\mathrm{Pt} / \mathrm{ZrC}$ catalysts prepared by a conventional chemical reduction method. After the stability test, the ECSA decreased by $17 \%$ for ALD-Pt/ZrC, whereas it decreased by $78 \%$ for commercial $\mathrm{Pt} / \mathrm{C}$. The excellent performance of the ALD-Pt/ZrC catalyst mainly originated from the high stability of the $\mathrm{ZrC}$ support and the strong metal-support interaction in the ALD-synthesized samples [14]. Pt electrocatalysts loaded on stable supports such as $\mathrm{MoS}_{2}$ and $\mathrm{Mo}_{2} \mathrm{C}$ have also been successfully synthesized through ALD, and they exhibit excellent activity and stability toward electrochemical reactions $[14,61,62]$.

\section{Noble bimetallic electrocatalysts}

\subsection{Common noble bimetallic electrocatalysts}

Bimetallic catalysts often exhibit higher catalytic performance than those of parent monometallic catalysts. This characteristic is mainly attributed to the synergetic effect of the two components and the electronic effect from the metal-metal bond formation $[63,64]$. The catalytic performance of bimetallic catalysts significantly depends on the particle composition, size, and structure. For example, Pt-Ru systems have been considered as a representative bimetallic electrocatalyst with high activity and stability toward alcohol electrooxidation in fuel cells. Pt plays a key role in the chemisorption and dissociation of alcohol molecules; however, it is easily poisoned by CO intermediates. $\mathrm{Ru}$ is capable of generating hydroxyl groups in the presence of water to effectively oxidize the intermediates adsorbed on the Pt surface and to release the poisoned Pt sites [65]. In this way, Pt and Ru synergistically facilitate the oxidation of alcohol. The content of $\mathrm{Ru}$ is crucial in synthesizing $\mathrm{Pt}-\mathrm{Ru}$ bimetallic catalysts since $\mathrm{Ru}$ promotes the oxidation of the intermediates; however, excess Ru reduces the ability of the catalyst to adsorb and activate reactant molecules because the surface content of $\mathrm{Pt}$ is reduced. In addition to $\mathrm{Ru}$, other metals have also been incorporated with Pt to enhance the electrocatalytic properties. Strasser et al. [66] reported that dealloyed binary $\mathrm{PtCo}_{3}, \mathrm{PtCu}_{3}$, and $\mathrm{PtNi}_{3}$ catalysts exhibited approximately 3 times higher ORR activity compared to that of a $45 \mathrm{wt} . \%$ $\mathrm{Pt} / \mathrm{C}$ reference catalyst. Wang et al. [67] found that the composition and structure of the Pt-Co bimetallic electrocatalyst greatly affected its activity toward methanol electrooxidation. The Pt-Co nanowire assemblies with the Pt/Co molar ratio of 3:1 outperformed commercial Pt catalyst and 3D Pt nanowire assemblies, which was attributed to the synergetic effects of the alloyed composition and the unique interconnected 3D structures [67].

The traditional methods for preparing bimetallic catalysts such as the impregnation, ion exchange, and colloidal methods often produce large nanoparticles and generate poor uniformity of particle sizes as well as heterogeneous compositions and phases $[68,69]$. The gas phase feature of ALD allows the direct deposition of bimetallic nanoparticles on supports without requiring post-treatment steps (purification and separation) common to solvent-based synthesis methods. The composition, size, and structure of bimetallic particles can be precisely controlled. Christensen et al. [70] synthesized Pt-Ru nanoparticles with diameters of approximately $1.2 \mathrm{~nm}$ (Fig. 6) by alternately applying ALD Pt and Ru procedures to the support. The $\mathrm{Ru} / \mathrm{Pt}$ ratio could be precisely controlled by adjusting the ratio of $\mathrm{Ru}$ to Pt ALD cycles [70]. Johansson et al. [71] prepared Ru-decorated Pt nanoparticles as a catalyst in direct methanol fuel cells. Ru was decorated in different amounts on Pt particles by varying the Ru ALD cycles. The catalytic activity was optimized with the catalyst decorated by 5 ALD Ru cycles [71]. Ramachandran et al. [72] synthesized Pt-Sn bimetallic nanoparticles by a two-step method. First, thin films of $\mathrm{SnO}_{2}$ and Pt were successively deposited on a support through the ALD method. Subsequently, the sample was reduced in $\mathrm{H}_{2}$ at a high temperature, and alloyed Pt-Sn nanoparticles were produced. The size and composition of the Pt-Sn bimetallic nanoparticles could be tuned by changing the thickness of the Pt and $\mathrm{SnO}_{2}$ layers [72]. In addition to the above, ALD has been successfully applied to synthesize Pt-Pd, Pt-Au, Pt-Ir, Pt-Co, Pt-Ni, and other bimetallic nanoparticles [69,72-75].

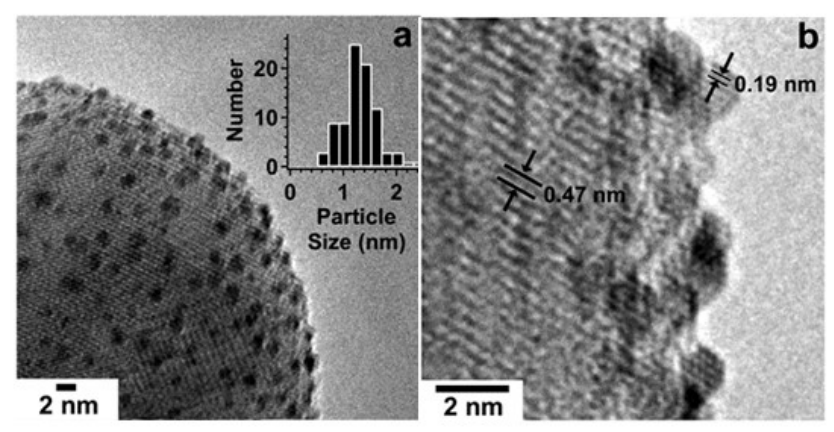

Fig. 6. TEM images of ALD Pt-Ru nanoparticles on $\mathrm{Al}_{2} \mathrm{O}_{3}$. The lattice fringes are $0.47 \mathrm{~nm}$ for the $\mathrm{Al}_{2} \mathrm{O}_{3}$ support and $0.19 \mathrm{~nm}$ for the nanoparticles [70]. (C) American Chemical Society 2010. 


\subsection{Noble bimetallic electrocatalysts with a core-shell structure}

Bimetallic nanoparticles with a core-shell structure have been proven to exhibit enhanced catalytic performance in comparison with that of alloyed bimetallic nanoparticles and mixtures of monometallic nanoparticles. For instance, a $\mathrm{Pt}_{3} \mathrm{Co}$ catalyst with a Co core and $\mathrm{Pt}$ shell structure exhibited a 2-times-higher mass activity and 3-times-higher specific activity toward the ORR compared to those of the alloyed $\mathrm{Pt}_{3}$ Co nanoparticles [76]. A catalyst with the structure of a Ru core and Pt shell performed better (an activity increase of up to 36\%) during methanol electrooxidation than did the commercial JM $\mathrm{Pt}-\mathrm{Ru}$ alloy catalyst [77]. The enhanced catalytic performance of the core-shell catalysts is attributed to the lattice strain, electron transfer, and bonding interaction at the core-shell interface [78].

The composition and thickness of the shell in core-shell nanoparticles greatly affect the catalytic properties [78,79]. Wet chemical synthesis methods usually generate core-shell particles by reducing a second metal onto the core. The precise control of the composition and shell thickness of the core-shell structure remains challenging for the solvent synthesis method [80]. ALD has unique advantages in synthesizing highly controllable bimetallic core-shell nanoparticles. Here are several strategies employing the ALD method to fabricate core-shell structures.

\subsubsection{Synthesizing core-shell structures by adjusting precursor reactants}

Kessel et al. [81] synthesized Pd@Pt bimetallic nanoparticles (Fig. 7a and 7b) by initially depositing Pd cores with palladium hexafluoroacetylacetonate $\left(\mathrm{Pd}(\mathrm{hfac})_{2}\right)$ and $\mathrm{H}_{2}$ plasma at $100{ }^{\circ} \mathrm{C}$, followed by depositing Pt using $\mathrm{MeCpPtMe}_{3}$ and $\mathrm{O}_{2}$ at $300{ }^{\circ} \mathrm{C}$. When the Pt ALD procedure was conducted at an $\mathrm{O}_{2}$ partial pressure lower than that of a normal Pt ALD process during the $\mathrm{O}_{2}$ pulse, $\mathrm{Pt}$ only grew on the surface of $\mathrm{Pd}$ and not on the surface of the $\mathrm{Al}_{2} \mathrm{O}_{3}$ support. The researchers speculated that at low $\mathrm{O}_{2}$ partial pressure, $\mathrm{O}_{2}$ only dissociatively chemisorbs on the active Pd surface and not on the less active $\mathrm{Al}_{2} \mathrm{O}_{3}$ support surface. Since the dissociative chemisorption of $\mathrm{O}_{2}$ is a key step in the reaction of Pt ALD, the absence of dissociated oxygen on the surface of an $\mathrm{Al}_{2} \mathrm{O}_{3}$ support would impede the reaction with the Pt precursor, thereby hindering the deposition of Pt. The size of the Pd core and the thickness of the Pt skin can be tuned by applying different ALD cycles for Pd and
Pt. When conducting Pt ALD at a high $\mathrm{O}_{2}$ partial pressure, Pt can be deposited on both Pd cores and the $\mathrm{Al}_{2} \mathrm{O}_{3}$ substrate. The researchers also synthesized Pt@Pd structures by initially depositing Pt cores, and subsequently a Pd skin (Fig. 7c). During the procedure for depositing $\mathrm{Pd}, \mathrm{H}_{2}$ was used instead of $\mathrm{H}_{2}$ plasma. $\mathrm{H}_{2}$ is less active than $\mathrm{H}_{2}$ plasma, and it dissociatively chemisorbs only on the surfaces of $\mathrm{Pt}$, not on the surface of $\mathrm{Al}_{2} \mathrm{O}_{3}$, leading to the selective growth of $\mathrm{Pd}$ on $\mathrm{Pt}$ [81].

\subsubsection{Synthesizing core-shell structures by adjusting the reaction temperature}

Elam et al. [82] developed a low-temperature selective ALD to synthesize bimetallic core-shell structures. When reducing the deposition temperature from 300 to $150{ }^{\circ} \mathrm{C}$, the authors found that Pt ALD was significantly suppressed on the surfaces of $\mathrm{Al}_{2} \mathrm{O}_{3}, \mathrm{TiO}_{2}$, and $\mathrm{ZrO}_{2}$, whereas the deposition was not influenced on the surfaces of $\mathrm{Pd}$ and $\mathrm{Ru}$ [82]. The synthesized Pt@Pd and Pd@Pt core-shell structures are displayed in Fig. 8.

\subsubsection{Synthesizing core-shell structures by area-selective deposition}

Chen et al. [83] synthesized core-shell nanoparticles by an area-selective ALD (AS-ALD) technique. AS-ALD is highly sensitive to the substrate surface condition, and the materials can be deposited only where required. For the preparation of a bimetallic core-shell structure, an octadecyltrichlorosilane (ODTS) self-assembled monolayer (SAM) with a pinhole structure was firstly deposited on the substrate. The first metal was deposited in the pinholes and formed the core. The other parts of the substrate were covered by ODTS, which presented inert methyl end groups, and the ALD was hindered. During the shell formation stage, the precursors for the shell metal were chemically adsorbed only on the surface of the deposited cores and not on the surface of the SAM. After ALD, the ODTS SAM was removed by annealing in an atmospheric environment. Figure 9 shows a schematic diagram of the fabrication of core-shell structures through AS-ALD. The composition, size, and shell thickness of the core-shell nanoparticles can be precisely tuned by adjusting the number of ALD cycles. The core-shell structures synthesized by AS-ALD can be realized using regular ALD procedures without special adjustments [83].

The ALD technique allows for the independent tuning of the core size and shell thickness by adjusting the number of ALD cycles. A core with multiple shells and other designed structures can be realized through the ALD technique with full con-
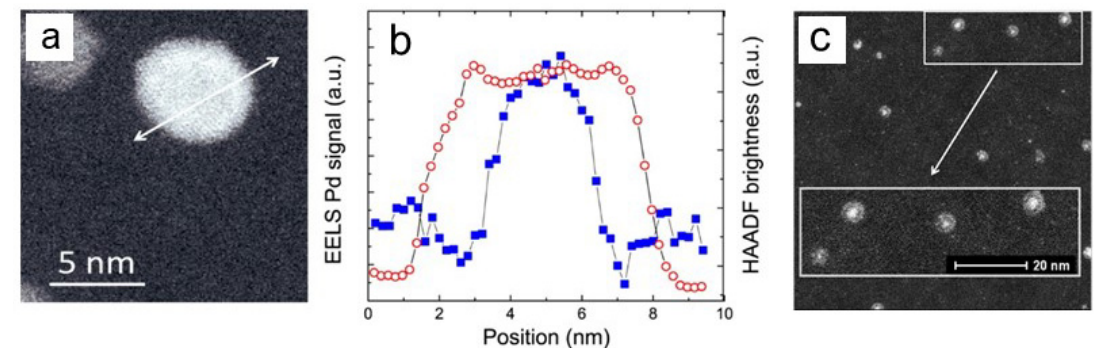

Fig. 7. (a) HAADF-STEM image of Pd@Pt core-shell nanoparticles and (b) an EELS line scan across a single Pd@Pt nanoparticle. (c) HAADF-STEM image of Pt@PdO core-shell nanoparticles [81]. C) American Chemical Society 2012. 

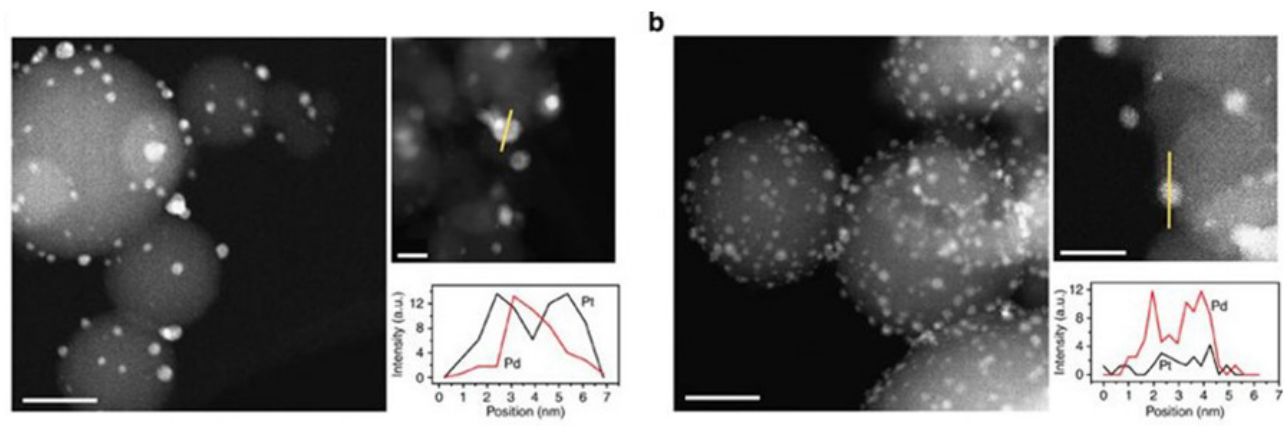

Fig. 8. Aberration-corrected HADDF-STEM images and corresponding EDS line profiles of (a) Pd@Pt and (b) Pt@PdO core-shell nanoparticles [82]. (c) Macmillan Publishers Limited 2014.

trol of the composition and dimensions.

\section{Non-noble metal electrocatalysts synthesized by ALD}

An ideal electrocatalyst should be highly active, stable, and economical. Although noble metal catalysts such as Pt, Pd, Ru, and Ir have shown excellent catalytic properties toward electrocatalysis, high-cost and scarcity hinder their large-scale application. Therefore, intensive efforts have been focused on exploring substituent non-noble metal electrocatalysts. To date, many transition metal compounds such as metal oxides, nitrides, carbides, and sulfides have been extensively investigated for their electrocatalytic properties. For instance, carbon materials decorated by $\mathrm{Fe}-\mathrm{N}_{\mathrm{x}}$ exhibit higher activities toward ORR compared to that of commercial Pt/C [84]. Li et al. [85] coated a $\mathrm{N}$-doped carbon shell on the surface of CoMoP nanocrystals (CoMoP@C). The synthesized CoMoP@C catalyst showed a higher HER activity comparable to that of commercial Pt/C and significantly enhanced stability. The excellent HER performance originated from the low free energy of $\mathrm{H}$ on the CoMoP cores and the function of the outer carbon shell [85]. Miao et al. [86] fabricated mesoporous $\mathrm{FeS}_{2}$ materials with high surface areas. The mesoporous $\mathrm{FeS}_{2}$ exhibited outstanding activity toward the HER. The catalyst possessed a low overpotential of $96 \mathrm{mV}$ to reach a current density of $10 \mathrm{~mA} \mathrm{~cm}^{-2}$ and a Tafel slope of $78 \mathrm{mV}$ per decade under alkaline conditions [86].

Although exhibiting good activity, transition metal compounds usually have low conductivity, which hampers elec-

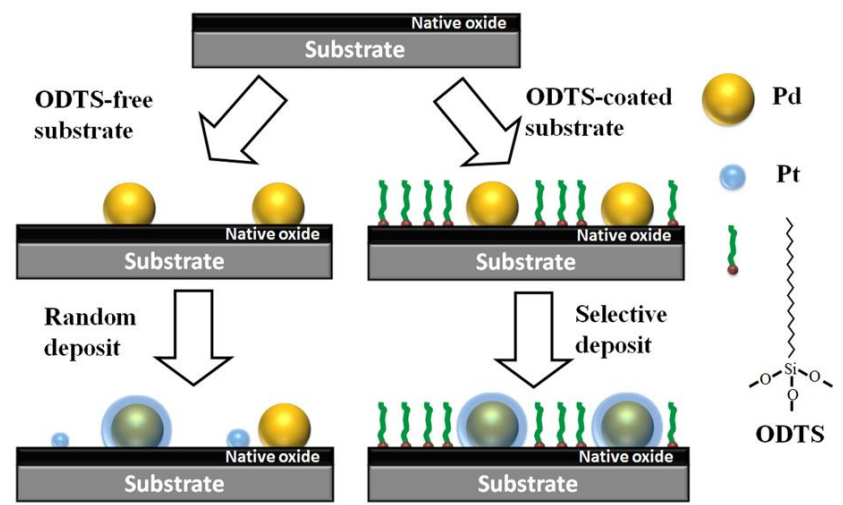

Fig. 9. Schematic for the fabrication of Pd@Pt core-shell nanoparticles through AS-ALD [83]. C Springer Nature Publishing AG 2015. tron/proton transfer during the electrocatalytic process. Incorporating transition metal compounds with carbon support, which has a high conductivity and large surface area, is desirable for obtaining advanced non-noble metal electrocatalysts. Besides, the large particle size, heterogeneous composition, and ambiguous structure of the catalysts prepared by normal methods result in a decreased atomic efficiency and hinder the gain of in-depth understanding of the catalytic mechanisms for highly active non-noble electrocatalysts [87]. One alternative synthetic route for synthesizing high-performance non-noble metal electrocatalysts is ALD.

\subsection{Transition metal oxide electrocatalysts}

Tong et al. [87] directly deposited uniform NiO nanoparticles on pristine CNTs. The activity toward the methanol electrooxidation of $\mathrm{NiO} / \mathrm{CNT}$ hybrids increased gradually as the $\mathrm{NiO}$ particle size increased from 1.5 to $4.9 \mathrm{~nm}$ and subsequently decreased rapidly when the particle size reached $4.9 \mathrm{~nm}$. The activity of the optimized NiO/CNT catalyst was approximately 88 times higher than that of commercial $\mathrm{NiO}$ nanopowder and was also superior in comparison with that of the reported NiO/CNTs synthesized by colloidal and hydrothermal methods $[88,89]$. The outstanding performance of ALD NiO/CNTs was attributed to the high dispersion and uniformity of the $\mathrm{NiO}$ nanoparticles [90]. Bent et al. [91] deposited conformal MnO films on glassy carbon; subsequently, $\mathrm{MnO}$ was converted into $\mathrm{Mn}_{2} \mathrm{O}_{3}$ after annealing. The $\mathrm{Mn}_{2} \mathrm{O}_{3}$ catalyst exhibited good activity toward both the ORR and OER. For the ORR, the $\mathrm{Mn}_{2} \mathrm{O}_{3}$ catalyst reached a half-wave current density of $-3 \mathrm{~mA} \mathrm{~cm}^{-2}$ at a potential of $0.71 \mathrm{~V}$, which was approximately $90 \mathrm{mV}$ better than that of the $\mathrm{Ru} / \mathrm{C}$ standard. For the OER, the $\mathrm{Mn}_{2} \mathrm{O}_{3}$ catalyst reached a current density of $10 \mathrm{~mA} \mathrm{~cm}^{-2}$ at $1.81 \mathrm{~V}$, which was $210 \mathrm{mV}$ better than that of $\mathrm{Pt} / \mathrm{C}$, but $190 \mathrm{mV}$ worse than that of the benchmark $\mathrm{Ru} / \mathrm{C}$ [91].

\subsection{Transition metal nitride electrocatalysts}

Perng et al. [92] deposited uniform copper nitride $\left(\mathrm{Cu}_{3} \mathrm{~N}\right)$ nanoparticles on CNTs through ALD using copper hexafluoroacetylacetonate $\left(\mathrm{Cu}(\mathrm{hfac})_{2}\right)$ and $\mathrm{NH}_{3}$ plasma as precursors. The authors found that the ORR activity of the catalyst was significantly influenced by the size of the $\mathrm{Cu}_{3} \mathrm{~N}$ particles. By optimiz- 
ing the $\mathrm{Cu}_{3} \mathrm{~N}$ particle size through varying the number of ALD cycles, the $\mathrm{Cu}_{3} \mathrm{~N} / \mathrm{CNTs}$ catalyst exhibited a remarkable electrocatalytic activity toward the ORR, with an onset potential of $-0.220 \mathrm{~V}$ and a half-wave potential of $-0.376 \mathrm{~V}$. The Koutecky-Levich analysis demonstrated the existence of a mixed two- and four-electron transfer mechanism for the hybrid $\mathrm{Cu}_{3} \mathrm{~N} @ \mathrm{CNT}$ electrode [92].

\subsection{Transition metal sulfide electrocatalysts}

Wang's group [93,94] developed a series of ALD recipes to synthesize sulfides of $\mathrm{Fe}, \mathrm{Co}$, and $\mathrm{Ni}$. $\mathrm{Cog}_{9} \mathrm{~S}_{8}$ thin films can be deposited using bis( $N, N^{\prime}$-diisopropylacetamidinato)cobalt(II) and $\mathrm{H}_{2} \mathrm{~S}$ as precursors. The $\mathrm{Co}_{9} \mathrm{~S}_{8} / \mathrm{CNT}$ sample exhibited excellent OER and ORR performance as an efficient bifunctional electrocatalyst. The material yielded a smaller overpotential for achieving the current density of $10 \mathrm{~mA} \mathrm{~cm}^{-2}$ and a smaller Tafel slope than those of $\mathrm{Ru}_{2} \mathrm{O}$ for the OER. Additionally, the current density decreased by less than $4 \%$ after a 20 -h test, proving $\mathrm{Co}_{9} \mathrm{~S}_{8} / \mathrm{CNT}$ s to be a very stable OER catalyst. The synthesized $\mathrm{Cog}_{8}$ /CNTs also exhibited excellent ORR activity, as the onset and half-wave potentials were only slightly lower than those of the commercial Pt/C catalyst. The outstanding performance of the $\mathrm{Cog}_{8}$ /CNT catalyst mostly arose from the highly conformal $\mathrm{Co}_{9} \mathrm{~S}_{8}$ coating prepared by ALD, which could fully exploit the surface of the CNTs to catalyze the reactions [93]. By employing $\mathrm{H}_{2} \mathrm{~S}$ plasma instead of $\mathrm{H}_{2} \mathrm{~S}$ as the sulfur source, a cobalt sulfide with a different stoichiometry, $\mathrm{CoS}_{2}$, was obtained [94].

$\mathrm{Ni}_{9} \mathrm{~S}_{8}$ was produced using bis $\left(N, N^{\prime}\right.$-di-tert-butylacetamidinato)nickel(II) (Ni(amd) $)_{2}$ ) and $\mathrm{H}_{2} \mathrm{~S}$ as the precursors. The $\mathrm{Ni}_{9} \mathrm{~S}_{8} / \mathrm{CNT}$ catalyst exhibited a better OER activity than that of the benchmark $\mathrm{RuO}_{2}$, and the activity was greatly enhanced upon electrochemical ageing. The activity enhancement was attributed to the nanoporous structures formed in situ during the OER, which could offer an increased surface area to expose more catalytic active sites [95]. In addition to $\mathrm{Ni}_{9} \mathrm{~S}_{8}, \mathrm{Ni}_{3} \mathrm{~S}_{2}, \mathrm{NiS}_{2}$, and amorphous $\mathrm{NiS}_{x}$ could also be synthesized through ALD by varying the precursors and the deposition temperature [96,97]. Generally, a relatively low deposition temperature favors the synthesis of amorphous nickel sulfides, while a relatively high deposition temperature favors the synthesis of crystalline nickel sulfide.

By alternately applying the ALD procedures for $\mathrm{FeS}_{\mathrm{x}}$ and $\mathrm{CoS}_{x}$, ternary $\mathrm{Fe}_{x} \mathrm{Co}_{1-x} \mathrm{~S}_{y}$-based catalysts were synthesized. The $\mathrm{Fe} / \mathrm{Co}$ ratio could be precisely tuned by controlling the ALD cycle ratio of $\mathrm{FeS}_{X}$ and $\mathrm{CoS}_{x}$ to optimize the catalyst composition. The optimized ternary $\mathrm{Fe}_{0.54} \mathrm{Co}_{0.46} \mathrm{~S}_{0.92}$ showed an enhanced HER activity compared to that of the binary sulfides. The catalyst activity was further improved by the structure optimization of coating the $\mathrm{Fe}_{x} \mathrm{Co}_{1-x} \mathrm{~S}_{y}$ thin-film on CNTs/CC (carbon nanotubes on carbon cloth) with a high surface area. The $\mathrm{Fe}_{x} \mathrm{Co}_{1-x} \mathrm{~S}_{y} / \mathrm{CNTs} / \mathrm{CC}$ exhibited an excellent HER performance comparable to that of the state-of-art Pt/C electrocatalyst [98]. Figure 10 illustrates the two-step strategy for optimizing the activity of an electrocatalyst by the ALD method.

Molybdenum disulfide $\left(\mathrm{MoS}_{2}\right)$ is a highly effective catalyst for the HER. MoS 2 consists of active catalytic edge sites and an

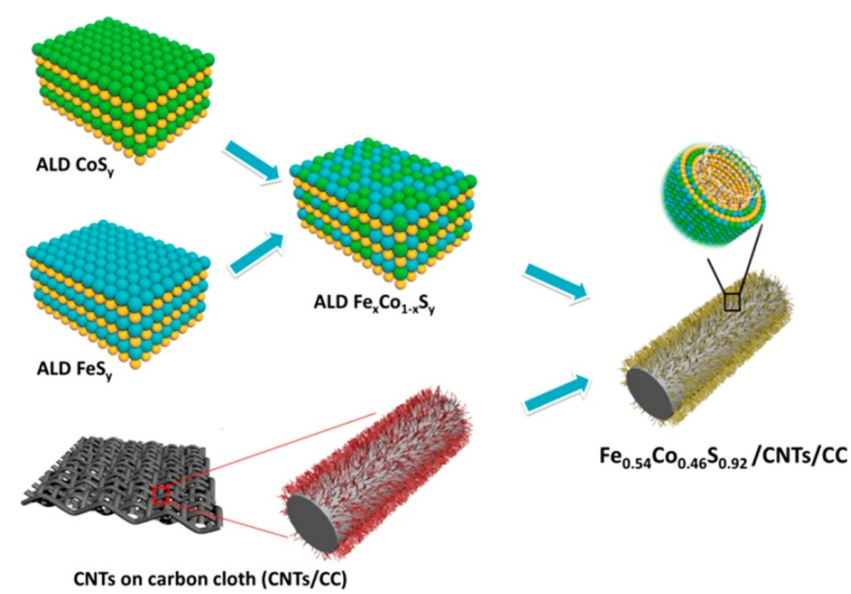

Fig. 10. Schematic of the ALD-based engineering strategy for the $\mathrm{Fe}_{\mathrm{x} \text { - }}$ $\mathrm{Co}_{1-x} \mathrm{~S}_{y} / \mathrm{CNTs} / \mathrm{CC}$ HER catalysts [98]. (C) American Chemical Society 2017.

inert basal plane. The activation of the basal plane is an effective method to enhance the HER activity of $\mathrm{MoS}_{2}$. Kim et al. [99] produced surface distortions in the $\mathrm{MoS}_{2}$ basal plane and significantly improved the HER performance of $\mathrm{MoS}_{2}$ by ALD and the in situ electrochemical activation method. First, a certain amount of $\mathrm{TiO}_{2}$ was deposited on commercial $\mathrm{MoS}_{2}$ by ALD. The $\mathrm{TiO}_{2}$ formed a thin layer at the $\mathrm{MoS}_{2}$ edge sites and isolated particles on the $\mathrm{MoS}_{2}$ basal plane. This configuration was owing to the presence of few sites reactive to the ALD precursors on the basal plane. Subsequently, the $\mathrm{TiO}_{2}$ films and particles coated on $\mathrm{MoS}_{2}$ were dissolved by the in situ electrochemical activation of repeating linear sweep voltammogram (LSV) experiments at a potential ranging from 0.286 to $-0.814 \mathrm{~V}$ versus a standard hydrogen electrode (SHE). Finally, atomic-scale surface distortions in the $\mathrm{MoS}_{2}$ basal plane were created with chemical reactions during the $\mathrm{TiO}_{2}$ coating and dissolution. The degree of surface distortion in the $\mathrm{MoS}_{2}$ basal planes could be modulated by controlling the $\mathrm{TiO}_{2}$ ALD cycles. The activated $\mathrm{MoS}_{2}$ samples were denoted as $\operatorname{ALD}($ Act.)-MoS2 and exhibited an enhanced activity and kinetics toward the HER because the induced surface distortions in the $\mathrm{MoS}_{2}$ basal plane facilitated the adsorption of hydrogen atoms during the reaction [99]. Figure 11a shows a schematic of the generation of highly localized surface distortions in the $\mathrm{MoS}_{2}$ basal plane via ALD and in situ electrochemical activation. Figures $11 \mathrm{~b}-11 \mathrm{~d}$ show the HRTEM images of pristine $\mathrm{MoS}_{2}, 50 \mathrm{ALD}\left(\mathrm{TiO}_{2}\right)-\mathrm{MoS}_{2}$, and $50 A L D(A c t)-.\mathrm{MoS}_{2}$ [99]. In addition to creating distortions and defects in the existing $\mathrm{MoS}_{2}$ materials, $\mathrm{MoS}_{x}$ materials with amorphous phase, crystalline phase, and mixed phase structures have been directly synthesized via the ALD method and applied in HER [100].

\subsection{Transition metal carbide electrocatalysts}

Transition metal carbides (TMCs) have emerged as intriguing materials due to their particular electronic structures, and they have shown potential for application in electrocatalysis [101-103]. TMCs such as $\mathrm{Ni}_{3} \mathrm{C}, \mathrm{Co}_{2} \mathrm{C}$, TiAlC, $\mathrm{WC}_{x}$, and $\mathrm{MoC}_{\mathrm{x}}$ have been successfully synthesized via the ALD method 
(a)

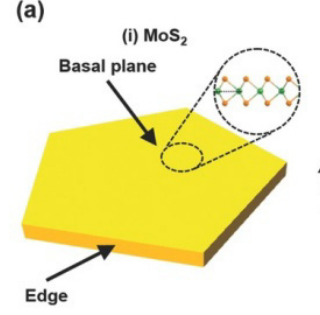

(b) $\mathrm{MoS}_{2}$ (bare)

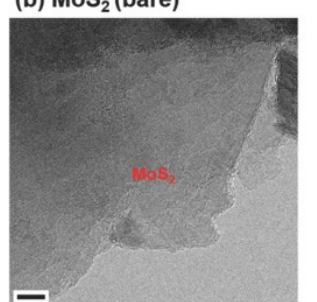

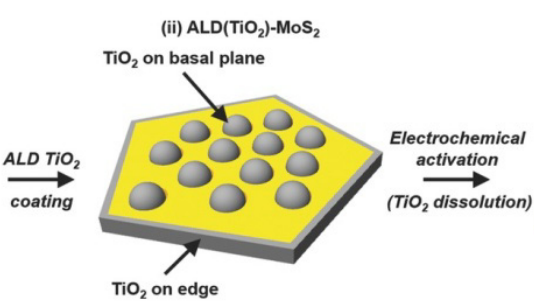

(c) $50 \mathrm{ALD}\left(\mathrm{TiO}_{2}\right)-\mathrm{MoS}_{2}$

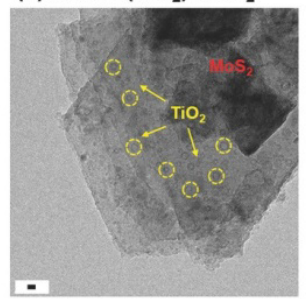

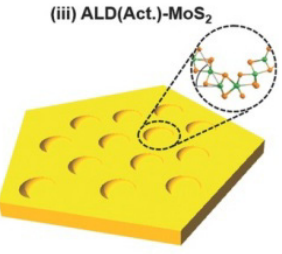

(d) 50ALD(Act.)-MoS

Fig. 11. (a) Schematic of the $\mathrm{ALD} \mathrm{TiO} 2$ coating on pristine $\mathrm{MoS}_{2}$ and the $\mathrm{TiO}_{2}$ dissolution by electrochemical activation. HRTEM images of (b) pristine $\mathrm{MoS}_{2}$, (c) 50ALD(TiO 2 )-MoS , and (d) 50ALD(Act.)-MoS [99]. (C) Wiley-VCH 2017.
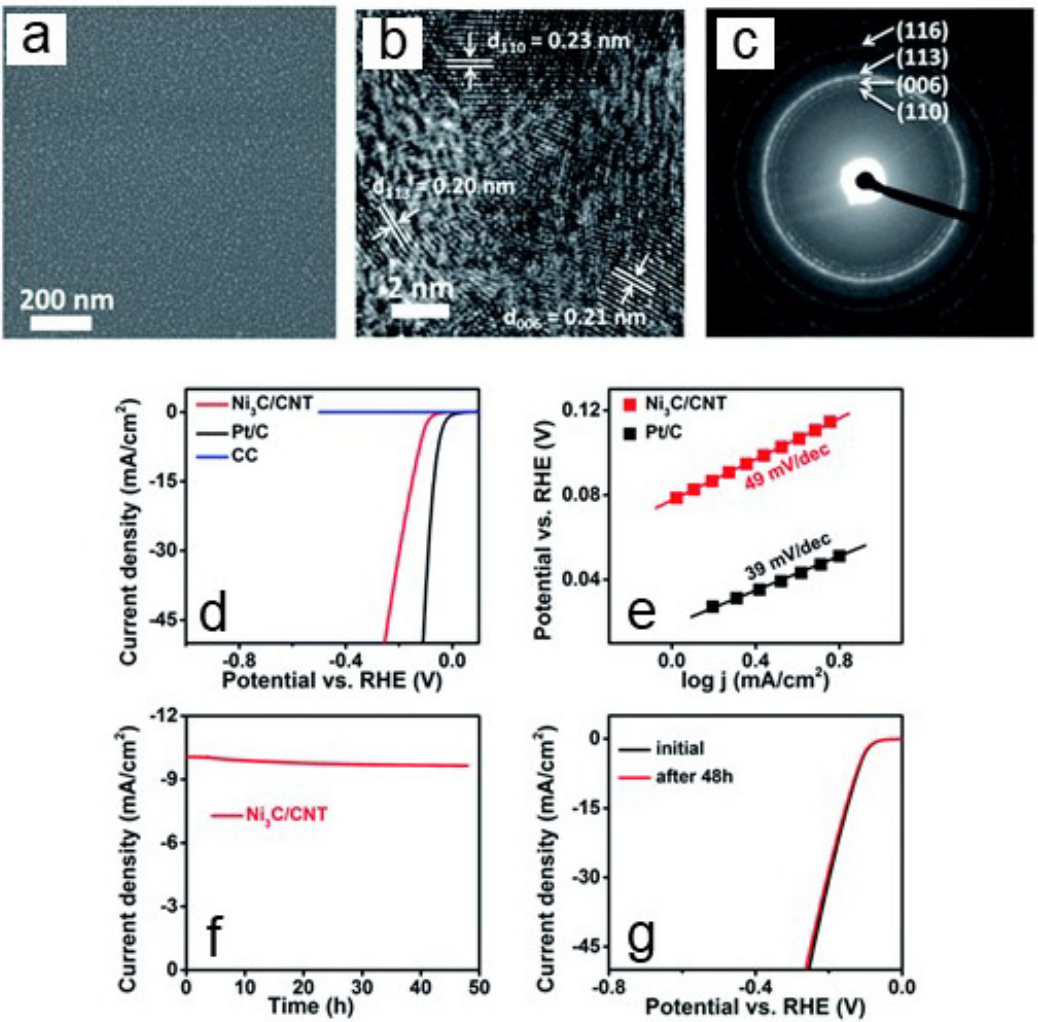

Fig. 12. (a) SEM image of a $\mathrm{Ni}_{3} \mathrm{C}$ film deposited by $300 \mathrm{ALD}$ cycles on a flat Si substrate. (b) TEM image and (c) the corresponding electron diffraction pattern of the ALD-synthesized $\mathrm{Ni}_{3} \mathrm{C} / \mathrm{CNT}$ catalyst. (d) LSV curves and (e) Tafel plots of the ALD Ni3 C/CNTs and state-of-the-art Pt/C catalyst. (f) Chronoamperogram of $\mathrm{Ni}_{3} \mathrm{C} / \mathrm{CNTs}$ at a constant overpotential bias of $-132 \mathrm{mV}$. (g) Comparison of the LSV curves of the ALD Ni $\mathrm{i}_{3} \mathrm{C} / \mathrm{CNTs}$ before and after $48 \mathrm{~h}$ of the chronoamperometric measurement [108]. (C) The Royal Society of Chemistry 2018.

[104-107]. Wang et al. [108] reported an ALD process for $\mathrm{Ni}_{3} \mathrm{C}$ using volatile nickel diazadienyl and $\mathrm{H}_{2}$ plasma as precursors. The deposition temperature could be as low as $95^{\circ} \mathrm{C}$ owing to the high volatility of the nickel diazadienyl precursor. Pure, smooth, and crystalline $\mathrm{Ni}_{3} \mathrm{C}$ films were obtained by the ALD process. By conformally depositing $\mathrm{Ni}_{3} \mathrm{C}$ thin films on CNTs, a core-shell structured $\mathrm{Ni}_{3} \mathrm{C} / \mathrm{CNT}$ composite was prepared. The $\mathrm{Ni}_{3} \mathrm{C} / \mathrm{CNTs}$ catalyst was proven to exhibit pronounced performance toward the HER with a small overpotential of $-132 \mathrm{mV}$ to achieve a current density of $-10 \mathrm{~mA} \mathrm{~cm}^{-2}$ and a Tafel slope of $49 \mathrm{mV}$ per decade. During a stability test at a constant overpotential of $-132 \mathrm{mV}$, the current density maintained $93 \%$ of its initial value after $48 \mathrm{~h}$, which indicated the superb stability of this ALD-produced catalyst [108]. The morphology, crystallinity, and HER performance of the as-synthesized $\mathrm{Ni}_{3} \mathrm{C} / \mathrm{CNT}$ s are presented in Fig. 12.

ALD provides an effective way to synthesize non-noble metal electrocatalysts. The approach allows the convenient opti- 
mization of active materials for a high specific activity by precisely controlling the material nano-features and composition. The optimization of the electrode geometry for a high surface-area can be achieved by fabricating conformal coating films on various nanostructured electrodes, such as a CNT network or carbon fiber cloth. As described above, the activities of some non-noble metal catalysts synthesized through ALD are comparable to those of state-of-the-art noble metal catalysts, such as $\mathrm{Pt} / \mathrm{C}$ or $\mathrm{Ru}_{2} \mathrm{O}$. These non-noble metal electrocatalysts synthesized through ALD exhibit good catalytic stability as well. More fundamentally, ALD enables the mechanism studies of non-noble metal catalysts by fabricating distinct catalyst surfaces of fairly pure, smooth, well-crystallized, and stoichiometric nanoparticles or thin films.

\section{Conclusions and perspectives}

ALD provides a promising and controllable approach to synthesizing electrocatalysts. In this review, various ALD strategies for preparing high-performance electrocatalysts are presented. Ultrafine catalytic nanoparticles can be conformally and uniformly deposited on supports in different morphologies, including various 1D, 2D, and 3D structures. For noble metallic Pt catalysts, the amount of Pt used and the cost of the catalyst can be significantly reduced. Furthermore, in the ALD process, the precursor molecules form chemical bonds with the functional groups on the support surface, and this generates a strong interaction between the catalytic metal nanoparticles and the support, which can help improve the catalytic activity and stability during electrocatalytic reactions. For synthesizing bimetallic catalysts with an alloy or core-shell structure, ALD enables the composition of alloys and the shell thickness of core-shell particles to be precisely controlled by adjusting the ALD cycle number or parameters. Additionally, ALD has been applied to synthesize non-noble metal electrocatalysts by producing transition metal oxides, nitrides, sulfides, and carbides and integrating these materials with porous and conductive supports via the deposition of conformal thin films to increase the catalyst specific surface area and activity. From the aspect of manufacturing novel nanostructured electrocatalysts, ALD offers unique advantages. Nanotraps, confinement, defects, selective deposition, ultrathin modification, and other structures have been successfully achieved through ALD to improve the properties of catalysts $[24,83,99,109,110]$. With atomic-level control of the catalyst composition and structure, ALD may facilitate the exploration of active sites and structure-property relationships, thereby promoting the rational design and synthesis of desired electrocatalysts.

However, there are still challenges in preparing electrocatalysts by ALD. The cost of commonly used ALD precursors is often higher than that of the compounds used for conventional impregnation or liquid phase synthesis. ALD on a large scale requires specialized ALD equipment, such as a rotary reactor or fluidized bed reactor. Therefore, the materials and equipment may increase the catalyst preparation cost. Furthermore, ALD procedures for new materials with electrocatalytic activity, particularly some non-noble metal materials, should be continuously exploited to meet the requirements of electrocatalyst development. Other advanced nanofabrication and in situ experimental techniques should also be combined with ALD to reveal the catalytic processes of electrochemical reactions and promote the design of new electrocatalysts.

\section{References}

[1] J. A. Turner, Science, 2004, 305, 972-974.

[2] S. Chu, A. Majumdar, Nature, 2012, 488, 294-303.

[3] T. Reier, M. Oezaslan, P. Strasser, ACS Catal., 2012, 2, 1765-1772.

[4] Z. W. Seh, J. Kibsgaard, C. F. Dickens, I. Chorkendorff, J. K. Nørskov, T. F. Jaramillo, Science, 2017, 355, eaad4998.

[5] Y. Nie, L. Li, Z. Wei, Chem. Soc. Rev., 2015, 44, 2168-2201.

[6] I. Ganesh, Renew. Sustain. Energy Rev., 2016, 59, 1269-1297.

[7] F. J. Vidal-Iglesias, N. Garcia-Araez, V. Montiel, J. M. Feliu, A. Aldaz, Electrochem. Commun., 2003, 5, 22-26.

[8] H. Liu, C. Song, L. Zhang, J. Zhang, H. Wang, D. P. Wilkinson, J. Power Sources, 2006, 155, 95-110.

[9] W. J. Zhou, Z. H. Zhou, S. Q. Song, W. Z. Li, W. Li, G. Q. Sun, P. Tsiakaras, Q. Xin, Appl. Catal. B: Environ., 2003, 46, 273-285.

[10] C. Rice, S. Ha, R. I. Masel, A. Wieckowski, J. Power Sources, 2003, 115, 229-235.

[11] L. Zhang, L. Han, H. Liu, X. Liu, J. Luo, Angew. Chem. Int. Ed., 2017,

\section{Graphical Abstract}

Chin. J. Catal., 2020, 41: 227-241 doi: S1872-2067(19)63440-6

\section{Application of atomic layer deposition in fabricating high-efficiency electrocatalysts}

Huimin Yang, Yao Chen, Yong Qin* Institute of Coal Chemistry, Chinese Academy of Sciences; Northwestern Polytechnical University

This review summarizes recent developments in atomic layer deposition (ALD) toward the design and synthesis of electrocatalysts, including different ALD strategies for improving the activity and stability of noble metal Pt electrocatalysts, noble bimetallic electrocatalysts, and non-noble metallic electrocatalysts.

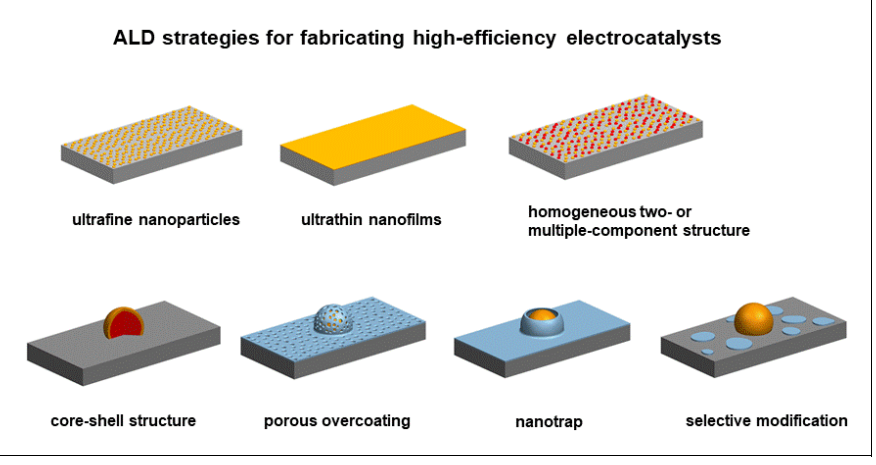


$56,13694-13698$.

[12] E. J. Yoo, T. Okata, T. Akita, M. Kohyama, J. Nakamura, I. Honma, Nano Lett., 2009, 9, 2255-2259.

[13] J. X. Wang, H. Inada, L. J. Wu, Y. M. Zhu, Y. M. Choi, P. Liu, W. P. Zhou, R. R. Adzic, J. Am. Chem. Soc., 2009, 131, 17298-17302.

[14] N. Cheng, M. Norouzi Banis, J. Liu, A. Riese, S. Mu, R. Li, T. K. Sham, X. Sun, Energy Environ. Sci., 2015, 8, 1450-1455.

[15] X. Cheng, Y. Li, L. Zheng, Y. Yan, Y. Zhang, G. Chen, S. Sun, J. Zhang, Energy Environ. Sci, 2017, 10, 2450-2458.

[16] H. Lv, S. Mu, N. Cheng, M. Pan, Appl. Catal. B: Environ., 2010, 100, 190-196.

[17] S. Yin, S. Mu, H. Lv, N. Cheng, M. Pan, Z. Fu, Appl. Catal. B: Environ., 2010, 93, 233-240.

[18] N. Cheng, S. Stambula, D. Wang, M. N. Banis, J. Liu, A. Riese, B. Xiao, R. Li, T. K. Sham, L. M. Liu, G. A. Botton, X. Sun, Nat. Commun., 2016, 7, 13638.

[19] C. Wang, F. Hu, H. Yang, Y. Zhang, H. Lu, Q. Wang, Nano Res., 2017, 10, 238-246.

[20] Y. Chen, S. Ji, Y. Wang, J. Dong, W. Chen, Z. Li, R. Shen, L. Zheng, Z. Zhuang, D. Wang, Y. Li, Angew. Chem. Int. Ed., 2017, 56, 6937-6941.

[21] M. C. Tsai, T. T. Nguyen, N. G. Akalework, C. J. Pan, J Rick, Y. F. Liao, W. N. Su, B. J. Hwang, ACS Catal., 2016, 6, 6551-6559.

[22] X. Han, F. Cheng, T. Zhang, J. Yang, Y. Hu, J. Chen, Adv. Mater., 2014, 26, 2047-2051.

[23] C. Meng, T. Ling, T. Y. Ma, H. Wang, Z. Hu, Y. Zhou, J. Mao, X. W. Du, M. Jaroniec, S. Z. Qiao, Adv. Mater., 2017, 29, 1604607.

[24] N. Cheng, M. N. Banis, J. Liu, A. Riese, X. Li, R. Li, S. Ye, S. Knights, X. Sun, Adv. Mater., 2015, 27, 277-281.

[25] J. Lu, P. C. Stair, Langmuir, 2010, 26, 16486-16495.

[26] V. R. Anderson, N. Leick, J. W. Clancey, K. E. Hurst, K. M. Jones, A. C. Dillon, S. M. George, J. Phys. Chem. C, 2014, 118, 8960-8970.

[27] M. Knez, K. Nielsch, L. Niinistö, Adv. Mater., 2007, 19, 3425-3438.

[28] T. Aaltonen, M. Ritala, T. Sajavaara, J. Keinonen, M. Leskelä, Chem. Mater., 2003, 15, 1924-1928.

[29] C. T. Hsieh, D. Y. Tzou, M. T. Jiang, J. Electroanal. Chem., 2017, 794, 139-147.

[30] J. L. Lu, J. W. Elam, P. C. Stair, Acc. Chem. Res., 2013, 46, 1806-1815.

[31] S. Sun, G. Zhang, N. Gauquelin, N. Chen, J. Zhou, S. Yang, W. Chen, X. Meng, D. Geng, M. N. Banis, R. Li, S. Ye, S. Knights, G. A. Botton, T. K. Sham, X. Sun, Sci. Rep., 2013, 3, 1775.

[32] E. Rikkinen, A. Santasalo-Aarnio, S. Airaksinen, M. Borghei, V. Viitanen, J. Sainio, E. I. Kauppinen, T. Kallio, A. O. I. Krause, J. Phys. Chem. C, 2011, 115, 23067-23073.

[33] C. T. Hsieh, Y. Y. Liu, D. Y. Tzou, Y. C. Chen, J. Taiwan Inst. Chem. Eng., 2014, 45, 186-191.

[34] X. Jiang, T. M. Gür, F. B. Prinz, S. F. Bent, Chem. Mater., 2010, 22, 3024-3032.

[35] W. Setthapun, W. D. Williams, S. M. Kim, H. Feng, J. W. Elam, F. A. Rabuffetti, K. R. Poeppelmeier, P. C. Stair, E. A. Stach, F. H. Ribeiro, J. T. Miller, C. L. Marshall, J. Phys. Chem. C, 2010, 114, 9758-9771.

[36] T. D. Gould, A. M. Lubers, A. R. Corpuz, A. W. Weimer, J. L. Falconer, J. W. Medlin, ACS Catal., 2015, 5, 1344-1352.

[37] C. Y. Su, Y. C. Hsueh, C. C. Kei, C. T. Lin, T. P. Perng, J. Phys. Chem. C, 2013, 117, 11610-11618.

[38] C. K. Poh, S. H. Lim, H. Pan, J. Lin, J. Y. Lee, J. Power Sources, 2008, $176,70-75$.

[39] Y. C. Hsueh, C. C. Wang, C. C. Kei, Y. H. Lin, C. Liu, T. P. Perng, J. Catal., 2012, 294, 63-68.

[40] C. T. Hsieh, W. Y. Chen, D. Y. Tzou, A. K. Roy, H. T. Hsiao, Int. J. Hy- drogen Energy, 2012, 37, 17837-17843.

[41] T. Shu, S. J. Liao, C. T. Hsieh, A. K. Roy, Y. Y. Liu, D. Y. Tzou, W. Y. Chen, Electrochim. Acta, 2012, 75, 101-107.

[42] C. T. Hsieh, H. T. Hsiao, D. Y. Tzou, P. Y. Yu, P. Y. Chen, B. S. Jang, Mater. Chem. Phys., 2015, 149-150, 359-367.

[43] A. A. Dameron, S. Pylypenko, J. B. Bult, K. C. Neyerlin, C. Engtrakul, C. Bochert, G. J. Leong, S. L. Frisco, L. Simpson, H. N. Dinh, B. Pivovar, Appl. Surf. Sci., 2012, 258, 5212-5221.

[44] J. Li, B. Zhang, Y. Chen, J. Zhang, H. Yang, J. Zhang, X. Lu, G. Li, Y. Qin, Catal. Sci. Technol., 2015, 5, 4218-4223.

[45] A. M. Lubers, C. L. Muhich, K. M. Anderson, A. W. Weimer, J. Nanopart. Res., 2015, 17, 1-16.

[46] T. Holme, Y. Zhou, R. Pasquarelli, R. O'Hayre, Phys. Chem. Chem. Phys., 2010, 12, 9461-9468.

[47] H. Yang, B. Zhang, B. Zhang, Z. Gao, Y. Qin, Chin. J. Catal,, 2018, 39, 1038-1043.

[48] S. Stambula, N. Gauquelin, M. Bugnet, S. Gorantla, S. Turner, S. Sun, J. Liu, G. Zhang, X. Sun, G. A. Botton, J. Phys. Chem. C, 2014, 118, 3890-3900.

[49] X. Liu, M. H. Liu, Y. C. Luo, C. Y. Mou, S. D. Lin, H. Cheng, J. M. Chen, J. F. Lee, T. S. Lin, J. Am. Chem. Soc., 2012, 134, 10251-10258.

[50] C. J. Pan, M. C. Tsai, W. N. Su, J. Rick, N. G. Akalework, A. K. Agegnehu, S. Y. Cheng, B. J. Hwang, J. Taiwan Inst. Chem. Eng., 2017, 74, 154-186.

[51] Y. Shao-Horn, W. C. Sheng, S. Chen, P. J. Ferreira, E. F. Holby, D. Morgan, Top. Catal., 2007, 46, 285-305.

[52] S. Saha, B. Martin, B. Leonard, D. Li, J. Mater. Chem. A, 2016, 4, 9253-9265.

[53] P. Nayak, Q. Jiang, N. Kurra, X. Wang, U. Buttner, H. N. Alshareef, J. Mater. Chem. A, 2017, 5, 20422-20427.

[54] J. Zhang, C. Chen, S. Chen, Q. Hu, Z. Gao, Y. Li, Y. Qin, Catal. Sci. Technol, 2017, 7, 322-329.

[55] H. B. R. Lee, S. F. Bent, Chem. Mater., 2015, 27, 6802-6809.

[56] H. Zhang, C. Cheng, J. Mater. Chem. A, 2016, 4, 15961-15967.

[57] S. Pulinthanathu Sree, J. Dendooven, L. Geerts, R. K. Ramachandran, E. Javon, F. Ceyssens, E. Breynaert, C. E. A. Kirschhock, R. Puers, T. Altantzis, G. Van Tendeloo, S. Bals, C. Detavernier, J. A. Martens, J. Mater. Chem. A, 2017, 5, 19007-19016.

[58] H. Feng, J. Lu, P. C. Stair, J. W. Elam, Catal. Lett., 2011, 141, 512-517.

[59] J. Lu, B. Fu, M. C. Kung, G. Xiao, J. W. Elam, H. H. Kung, P. C. Stair, Science, 2012, 335, 1205-1208.

[60] C. Marichy, G. Ercolano, G. Caputo, M. G. Willinger, D. Jones, J. Rozière, N. Pinna, S. Cavaliere, J. Mater. Chem. A, 2016, 4, 969-975.

[61] W. Ren, H. Zhang, C. Cheng, Electrochim. Acta, 2017, 241, 316-322.

[62] S. Saha, J. A. Cabrera Rodas, S. Tan, D. Li, J. Power Sources, 2018, $378,742-749$.

[63] F. Gao, D. W. Goodman, Chem. Soc. Rev., 2012, 41, 8009-8020.

[64] F. Maroun, F. Ozanam, O. M. Magnussen, R. J. Behm, Science, 2001, 293, 1811-1814.

[65] O. A. Petrii,J. Solid State Electrochem., 2008, 12, 609-642.

[66] P. Mani, R. Srivastava, P. Strasser, J. Power Sources, 2011, 196, 666-673.

[67] B. Y. Xia, H. B. Wu, N. Li, Y. Yan, X. W. Lou, X. Wang, Angew. Chem. Int. Ed., 2015, 54, 3797-3801.

[68] S. Duan, R. Wang, Prog. Nat. Sci.: Mater. Int., 2013, 23, 113-126.

[69] R. K. Ramachandran, J. Dendooven, M. Filez, V. V. Galvita, H. Poelman, E. Solano, M. M. Minjauw, K. Devloo-Casier, E. Fonda, D. Hermida-Merino, W. Bras, G.B. Marin, C. Detavernier, ACS Nano, 2016, 10, 8770-8777.

[70] S. T. Christensen, H. Feng, J. L. Libera, N. Guo, J. T. Miller, P. C. Stair, J. W. Elam, Nano Lett., 2010, 10, 3047-3051. 
[71] A. C. Johansson, R. B. Yang, K. B. Haugshøj, J. V. Larsen, L. H. Christensen, E. V. Thomsen, Int. J. Hydrogen Energy, 2013, 38, 11406-11414.

[72] R. K. Ramachandran, M. Filez, J. Dendooven, V. V. Galvita, H. Poelman, E. Solano, E. Fonda, G. B. Marin, C. Detavernier, RSC Adv., 2017, 7, 20201-20205.

[73] H. Wang, C. Wang, H. Yan, H. Yi, J. Lu, J. Catal., 2015, 324, 59-68.

[74] A. S. Aarnio, E. Sairanen, R. M. Arán-Ais, M. C. Figueiredo, J. Hua, J. M. Feliu, J. Lehtonen, R. Karinen, T. Kallio, J. Catal., 2014, 309, 38-48.

[75] S. T. Christensen, J. W. Elam, Chem. Mater., 2010, 22, 2517-2525.

[76] D. Wang, H. L. Xin, R. Hovden, H. Wang, Y. Yu, D. A. Muller, F. J. Di Salvo, H. D. Abruna, Nat. Mater., 2013, 12, 81-87.

[77] D. Kaplan, M. Alon, L. Burstein, Y. Rosenberg, E. Peled, J. Power Sources, 2011, 196, 1078-1083.

[78] X. Wang, Y. Orikasa, Y. Takesue, H. Inoue, M. Nakamura, T. Minato, N. Hoshi, Y. Uchimoto, J. Am. Chem. Soc., 2013, 135, 5938-5941.

[79] S. Xie, S.I. Choi, N. Lu, L. T. Roling, J.A. Herron, L. Zhang, J. Park, J. Wang, M. J. Kim, Z. Xie, M. Mavrikakis, Y. Xia, Nano Lett., 2014, 14, 3570-3576.

[80] H. Yang, Angew. Chem. Int. Ed., 2011, 50, 2674-2676.

[81] M. J. Weber, A. J. M. Mackus, M. A. Verheijen, C. van der Marel, W. M. M. Kessels, Chem. Mater., 2012, 24, 2973-2977.

[82] J. Lu, K. B. Low, Y. Lei, J. A. Libera, A. Nicholls, P. C. Stair, J. W. Elam, Nat. Commun., 2014, 5, 4264.

[83] K. Cao, Q. Zhu, B. Shan, R. Chen, Sci. Rep., 2015, 5, 8470.

[84] Y. C. Wang, Y. J. Lai, L. Song, Z. Y. Zhou, J. G. Liu, Q. Wang, X. D. Yang, C. Chen, W. Shi, Y. P. Zheng, M. Rauf, S. G. Sun, Angew. Chem. Int. Ed., 2015, 54, 9907-9910.

[85] Y. Y. Ma, C. X. Wu, X. J. Feng, H. Q. Tan, L. K. Yan, Y. Liu, Z. H. Kang, E. B. Wang, Y. G. Li, Energy Environ. Sci., 2017, 10, 788-798.

[86] R. Miao, B. Dutta, S. Sahoo, J. He, W. Zhong, S. A. Cetegen, T. Jiang, S. P. Alpay, S. L. Suib, J. Am. Chem. Soc., 2017, 139, 13604-13607.

[87] P. Chen, T. Zhou, L. Xing, K. Xu, Y. Tong, H. Xie, L. Zhang, W. Yan, W. Chu, C. Wu, Y. Xie, Angew. Chem. Int. Ed., 2017, 56, 610-614.

[88] S. H. Nam, Y. S. Kim, H. S. Shim, S. M. Choi, H. J. Kim, W. B. Kim, J. Nanosci. Nanotechnol., 2008, 8, 5427-5432.

[89] P. Lin, Q. She, B. Hong, X. J. Liu, Y. Shi, Z. Shi, M. Zheng, Q. Dong, J. Electrochem. Soc., 2010, 157, A818-A823.

[90] X. Tong, Y. Qin, X. Guo, O. Moutanabbir, X. Ao, E. Pippel, L. Zhang,
M. Knez, Small, 2012, 8, 3390-3395.

[91] K. L. Pickrahn, S. W. Park, Y. Gorlin, H. B. R. Lee, T. F. Jaramillo, S. F. Bent, Adv. Energy Mater., 2012, 2, 1269-1277.

[92] C. Y. Su, B. H. Liu, T. J. Lin, Y. M. Chi, C. C. Kei, K. W. Wang, T. P. Perng, J. Mater. Chem. A, 2015, 3, 18983-18990.

[93] H. Li, Z. Guo, X. Wang, J. Mater. Chem. A, 2017, 5, 21353-21361.

[94] Z. Guo, X. Wang, Angew. Chem. Int. Ed., 2018, 57, 5898-5920.

[95] H. Li, Y. Shao, Y. Su, Y. Gao, X. Wang, Chem. Mater., 2016, 28, 1155-1164.

[96] T. A. Ho, C. Bae, H. Nam, E. Kim, S. Y. Lee, J. H. Park, H. Shin, ACS Appl. Mater. Interfaces, 2018, 10, 12807-12815.

[97] Y. Cimen, A. W. Peters, J. R. Avila, W. L. Hoffeditz, S. Goswami, O. K. Farha, J. T. Hupp, Langmuir, 2016, 32, 12005-12012.

[98] W. Xiong, Z. Guo, H. Li, R. Zhao, X. Wang, ACS Energy Lett., 2017, 2, 2778-2785.

[99] Y. Kim, D. H. K. Jackson, D. Lee, M. Choi, T. W. Kim, S. Y. Jeong, H. J. Chae, H. W. Kim, N. Park, H. Chang, T. F. Kuech, H. J. Kim, Adv. Funct. Mater., 2017, 27, 1701825.

[100] S. Oh, J. B. Kim, J. T. Song, J. Oh, S. H. Kim, J. Mater. Chem A, 2017, 5, 3304-3310.

[101] Y. Gogotsi, Nat. Mater., 2015, 14, 1079-1080.

[102] B. Anasori, M. R. Lukatskaya, Y. Gogotsi, Nat. Rev. Mater., 2017, 2, 16098.

[103] H. H. Hwu, J. G. Chen, Chem. Rev., 2005, 105, 185-212.

[104] M. Sarr, N. Bahlawane, D. Arl, M. Dossot, E. McRae, D. Lenoble, J. Phys. Chem. C, 2014, 118, 23385-23392.

[105] M. Sarr, N. Bahlawane, D. Arl, M. Dossot, E. McRae, D. Lenoble, Appl. Surf. Sci., 2016, 379, 523-529.

[106] J. Moon, H. J. Ahn, Y. Seo, T. I. Lee, C. K. Kim, I. C. Rho, C. H. Kim, W. S. Hwang, B. J. Cho, IEEE Trans. Electron Devices, 2016, 63, 1423-1427.

[107] A. Bertuch, B. D. Keller, N. Ferralis, J. C. Grossman, G. Sundaram, J. Vac. Sci. Technol. A, 2017, 35, 01B141.

[108] W. Xiong, Q. Guo, Z. Guo, H. Li, R. Zhao, Q. Chen, Z. Liu, X. Wang, J. Mater. Chem. A, 2018, 6, 4297-4304.

[109] M. Wang, Z. Gao, B. Zhang, H. Yang, Y. Qiao, S. Chen, H. Ge, J. Zhang, Y. Qin, Chem.-Eur. J., 2016, 22, 8438-8443.

[110] Z. Gao, M. Dong, G. Wang, P. Sheng, Z. Wu, H. Yang, B. Zhang, G. Wang, J. Wang, Y. Qin, Angew. Chem. Int. Ed., 2015, 54, 9006-9010.

\section{原子层沉积方法在设计制备高效电催化剂中的应用

\author{
杨慧敏 ${ }^{\mathrm{a}}$, 陈 耀, 覃 勇a, \\ a 中国科学院山西煤炭化学研究所煤转化国家重点实验室, 山西太原030001

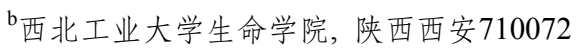

摘要: 人类对不可再生化石能源的依赖导致了全球范围内的能源危机和环境污染. 电化学能源转换技术由于具有清洁、高 效、原料来源广泛及可再生等优点而受到广泛关注. 电催化剂能加快反应动力学, 提高目标产物选择性, 在电化学能源转 换技术中起着至关重要的作用. 目前, Pt是多数重要的电化学反应(如电解水、氧还原以及一些小分子醇类和酸类的氧化反 应)中使用最多和最有效的催化剂之一. 然而Pt催化剂面临着价格昂贵、易中毒、易流失等问题, 使其在大规模工业化应用 中受到限制. 为了提高Pt催化剂的利用率和稳定性, 研究人员进行了大量工作. 例如, 制备尺寸小的Pt纳米颗粒, 增加单位 质量 $\mathrm{Pt}$ 表面积和 $\mathrm{Pt}$ 利用率; 在 $\mathrm{Pt}$ 催化剂中加入 $\mathrm{Ru}$ 或 $\mathrm{Pd}$ 等其它金属, 促进醇类和酸类氧化反应中间产物的氧化, 减缓 $\mathrm{Pt}$ 中毒; 选用抗腐蚀性能好的载体, 增加 $\mathrm{Pt}$ 与载体间相互作用, 从而抑制 $\mathrm{Pt}$ 颗粒在高电位、高湿度、高酸碱度电化学工作环境中的脱 落和聚集. 尽管如此, 利用传统的方法仍然很难精确调控电催化剂的组成、尺寸和纳米结构, 无法最大程度提高贵金属 $\mathrm{Pt}$ 的利用效率. 原子层沉积(ALD)技术可在原子尺度控制物质生长, 既能在多孔、复杂基体上沉积尺度均一的纳米薄膜或颗 粒, 也能精确调控、构筑各类纳米结构. 本文总结了近年来利用ALD技术制备高性能电催化剂的代表性研究进展. 
文章首先介绍了ALD反应机理、载体表面官能团对ALD生长的促进作用以及ALD制备方法对催化剂金属-载体相互作 用的影响等基本原理和知识. 总结了利用ALD技术制备高活性Pt催化剂的各种方法, 包括制备超细纳米颗粒, 纳米线、纳米 薄膜、纳米管, 纳米 $3 \mathrm{D}$ 结构等不同形貌 $\mathrm{Pt}$ 催化剂等. 介绍并探讨了利用 $\mathrm{ALD}$ 构筑纳米陷阱、包覆超薄多孔碳膜/氧化物膜、 选择性修饰载体等提高Pt催化剂稳定性的策略. 文章还介绍了如何通过调节ALD反应温度、前驱体种类, 以及利用选择性 沉积等方法, 精确调控双贵金属电催化剂中金属的比例、尺寸、结构等以提高催化剂性能, 并重点阐述了双金属核壳催化 剂的制备方法. 此外, 文章还概述了ALD方法制备非贵金属催化剂的研究进展. 最后, 文章总结了ALD技术在设计、制备电 催化剂领域的优势和不足, 展望了ALD在该领域的发展和应用前景, 为设计、制备高性能电催化剂提供了参考.

关键词: 原子层沉积; 电催化; 铂; 催化剂稳定性; 金属-载体相互作用

收稿日期: 2019-05-17. 接受日期: 2019-07-05. 出版日期: 2020-02-05.

*通讯联系人. 电话/传真: (0351)4040081; 电子信箱: qinyong@sxicc.ac.cn

基金来源: 国家自然科学基金(21872160,21802094, 21673269); 国家杰出青年科学基金(21825204); 国家重点研发计划 (2017YFA0700101); 陕西省自然科学基金(2018JQ2038).

本文的电子版全文由Elsevier出版社在ScienceDirect上出版(http://www.sciencedirect.com/science/journal/18722067). 